CONSERVACÃ̃O E RESTAURACÃO 


\title{
A restauração na trajetória de um teodolito do acervo do MAST'
}

\author{
Marcus Granato ${ }^{2}$ \\ Luiz Roberto Martins de Miranda
}

RESUMO: O Museu de Astronomia e Ciências Afins (MAST) é um museu de ciência e técnica situado no conjunto arquitetônico e paisagístico que pertenceu ao antigo Observatório Nacional, na cidade do Rio de Janeiro. No âmbito da criação do museu, o patrimônio de valor histórico ali existente, relacionado a período importante da história da ciência do Brasil, foi tombado pelo Instituto do Patrimônio Histórico e Artístico Nacional (Iphan) em 1986, e pelo Instituto Estadual do Patrimônio Cultural (Inepac) em 1987. Os estudos que resultaram na restauração de um teodolito da coleção do MAST iniciaram-se a partir de uma avaliação do estado de conservação da coleção de instrumentos científicos da instituição, possibilitando a seleção, segundo critérios pré-estabelecidos, desse objeto, que se encontrava em situação crítica de conservação. Seguiu-se pesquisa histórica sobre o instrumento, determinação da composição de suas peças principais, estudo sobre seu funcionamento e, finalmente, a intervenção propriamente dita sobre o objeto. $\bigcirc$ procedimento de restauração foi dividido em três etapas - conservação de peças, restauração de peças, e substituição de partes faltantes -, sendo acompanhado pelo registro fotográfico exaustivo de todas elas. Esse procedimento, implantado com esse estudo, possibilitou outras intervenções posteriores de restauração. desenvolvimento dos estudos de conservação de artefatos científicos e, por outro lado, aquele de pesquisas relacionadas à construção de trajetórias de objetos e coleções no âmbito do Grupo de Preservação de Acervos, sediado no MAST, possibilitou identificar a restauração como momento singular dessas trajetórias.

PALAVRAS-CHAVE: Restauração. Instrumento Científico. Teodolito. Brunner Frères

ABSTRACT: MAST is a science and technology museum located in the grounds and architectural complex belonging to the former National Observatory in Rio de Janeiro. Soon after the museum was created, the historical heritage existing there, relating to a significant period in the history of science in Brazil, was listed by the Brazilian National Heritage Institute (Iphan) and the Rio de Janeiro State Cultural Heritage Institute (Inepac) in 1986 and 1987, respectively. The studies that preceded the restoration of a theodolite from the MAST collection started with an appraisal of the state of conservation of the institution's scientific instruments collection.
1. Trabalho produzido a partir da tese de doutorado em engenharia metalúrgica e de materiais de Marcus Granato (Coppe-UFRJ).

2. Engenheiro Metalúrgico, D Sc., Coordenador de Museologia do Museu de Astronomia e Ciências Afins, do Ministério de Ciências eTecnologia.E-mail:<marcus@mast. br>. Museu de Astronomia e Ciências Afins, rua Gal. Bruce, 586, Bairro Imperial de São Cristóvão, Rio de Janeiro, Brasil. Site: <http://www. mast.br>.

3. Engenheiro Metalúrgico, D. Sc., Professor aposentado da Universidade Federal do Rio de Janeiro. E-mail: <luizdemi randa80@gmail.com>. 
4. Ver Paolo Brenni (2000).

5. Ver Maria Alice C. de Oliveira, (2011); Felipe Koeller R.Vieira (2009); e Roberta N. da Câmara (2008).

6.Ver José Reginaldo S. Gonçalves (2001).

7. Os objetos mais facilmente identificados ao patrimônio cultural de C\&T são os denominados instrumentos científicos, pois fizeram parte das atividades realizadas em laboratórios científicos e de tecnologia aplicada. No entanto, instrumento científico é um termo complexo e só se aplica a um determinado período histórico (século XIX e início do século XX) De forma mais ampla, utilizaremos objetos de ciência e tecnologia, como termo mais geral e que engloba a variedade de artefatos considerados nesses estudos; ver Marcus Granato e colaboradores (2007).
Next, a set of pre-established criteria were used to select this object, which was in a critical state of conservation. After this, historical research was undertaken of the instrument, the composition of its main parts was determined, a study was made into its working, and finally the intervention per se was undertaken on the object. The restoration procedure involved three stages: the conservation of parts, the restoration of parts, and the replacement of missing parts. The whole process was photographed exhaustively. The procedure adopted in this study has been replicated in further restoration projects. Studies were undertaken into the conservation of scientific instruments and research was done into the construction of trajectories of objects and collections by the Archive Preservation Group, based at MAST, resulting in the identification of restoration as a singular moment in these trajectories.

KEYWORDS: Restoration. Scientific Instrument. Theodolite. Brunner Frères.

Introdução

Cada geração constrói o patrimônio cultural que assimila as obras do passado. É uma característica humana, que todo o resto do mundo vivo - animal ou vegetal - desconhece. Encerra em si o que o homem, sob as formas oral e plástica, sabe transmitir a outros humanos acerca da experiência cultural que teve na vida. $\bigcirc$ patrimônio cultural não é legado graças a reflexos instintivos genéticos mas, sim, graças a um aprendizado reflexivo, que adapta cada conhecimento adquirido à situação particular daquele momento.

A coleção de instrumentos científicos do Museu de Astronomia e Ciências Afins (MAST) é considerada das mais representativas do gênero ${ }^{4}$. Restrito inicialmente a objetos provenientes do Observatório Nacional, o acervo do MAST vem sendo ampliado, mais recentemente, com a coleta de objetos provenientes do Instituto de Engenharia Nuclear (IEN), do Centro de Tecnologia Mineral (Cetem) e do Centro Brasileiro de Pesquisas Físicas (CBPF).

As atividades de preservação realizadas em torno da coleção de instrumentos científicos do MAST determinaram o início de pesquisas sobre o patrimônio cultural relacionado à ciência e à técnica, na esfera de atuação do Grupo de Pesquisas em Preservação de Acervos Culturais (GPAC), sediado no Museu. O advento do Programa de Pós-Graduação em Museologia e Patrimônio (PPG-PMUS), que o MAST e a Universidade Federal do Estado do Rio de Janeiro (Unirio) realizam em parceria, determinou o aprofundamento das reflexões sobre o assunto e o desenvolvimento de algumas dissertações em torno do tema ${ }^{5}$.

Configurados na produção artística ou nos artefatos de uso cotidiano, os objetos têm sido preteridos como fonte de análise histórica em muitas correntes historiográficas, apesar de sua força discursiva 6 . Por outro lado, obras de arte e objetos somente têm existência através de sua relação com a sociedade, caso contrário seus discursos são inexistentes. No caso do patrimônio cultural relacionado à Ciência e Tecnologia (C\&T), aqueles objetos ${ }^{7}$ que são testemunhos dos processos científicos e do desenvolvimento tecnológico não são mais utilizados para reproduzir, questionar ou estudar os fenômenos físicos. Não mantêm, 
portanto, o mesmo valor de uso comum, no caso o funcional, mas um valor, agora redimensionado, baseado em seu significado e nas informações que podemos obter a partir deles.

Em uma das frentes de estudo do GPAC, foi pesquisada uma metodologia de abordagem que possibilitasse trabalhar como fonte histórica os objetos de C\&T do MAST. As pesquisas realizadas permitiram verificar que, no exterior, alguns grupos de pesquisa já fazem trabalhos interessantes e instigantes utilizando esses objetos ${ }^{8}$. Foi possivel perceber que é possível não apenas tratar - objeto de C\&T como fonte para história, mas que, atualmente lao menos no exterior), ele já constitui um novo domínio historiográfico, que vem se fortalecendo nos últimos anos, com vários pesquisadores importantes desenvolvendo pesquisas e estudos a respeito.

O historiador Jim Bennett, por exemplo, desenvolve a construção da trajetória de instrumentos científicos tendo como ponto de partida o momento de sua fabricação, passando pelos diversos usos que possa ter tido em seu período de atividade funcional para, em alguns casos, chegar a um momento singular, em que é incorporado a uma coleção. Adquire, assim, função e significação novas, ao iniciar sua trajetória interna dentro da coleção. Não devem ser esquecidas, segundo esse autor, as mudanças sociais, políticas, culturais e econômicas que poderiam influenciar a instituição detentora da coleção e, consequentemente, os artefatos que a constituem?.

Samuel Alberti, historiador de coleções e museus de história natural, desenvolve estudos sobre a história dos museus a partir dos objetos existentes em suas coleções. Utiliza, para isso, o conceito de biografia cultural dos objetos, proposto pela antropologia. Para ele, o momento mais importante nessa biografia seria o da sua incorporação por uma instituição museológica ${ }^{10}$. A esse momento nós denominamos momentum museologicum, no qual o objeto perde seu valor funcional e de uso, assumindo valores e significados novos no âmbito da instituição Museu.

Numa outra frente de pesquisa do GPAC, foram avaliados modelos de leitura para objetos culturais, propiciando melhor entendimento tanto sobre cultura material, quanto acerca da questão da interpretação de objetos musealizados, permitindo ampliar o conhecimento sobre os artefatos trabalhados e seus fabricantes.

Finalmente, uma terceira área de estudo refere-se à conservaçãorestauração de objetos culturais, âmbito em que alguns resultados interessantes já foram alcançados e publicados ${ }^{11}$.

Nessas diversas frentes de pesquisa, os estudos se articulam e permitem verificar que a etapa de restauro por que passa um artefato constitui uma das singularidades de sua trajetória interna em uma coleção. Na verdade, trata-se de momento determinante na biografia de qualquer objeto cultural, sendo a ele agregada uma variedade de informações, ampliando-se o conhecimento a seu respeito - mas pode, também, determinar alterações substanciais e mesmo sua descaracterização, com perda definitiva de marcas históricas e de registros que
8. Ver Marcus Granato e colaboradores (2007); e ainda Janaina L. Furtado (2009).

9. Ver Jim Bennett (2005).

10. Cf. Samuel J. J. M. Alberti (2005, p. 560).

11. Ver Marcus Granato e colaboradores $(2005 ; 2009)$ 
12. Ver idem, 2006

13. Distância zenital: medida de posição de um astro no sistema horizontal (local) de coordenadas. Consiste no ângulo contado a partir da vertical local até a linha de visada do astro, sendo igual a $0^{\circ}$ no zênite e a $90^{\circ}$ no horizonte; ver Ronaldo R. de F. Mourão (1995).

14.Azimute: medida de posição de um astro no sistema horizontal (local) de coordenadas. Consiste no ângulo, contado ao longo do plano horizontal, entre o plano meridiano e o vertical do astro; ver Ronaldo R. de F. Mourão (1995). são particulares ao objeto. Pode ser, portanto, um momento muito positivo - ou desastroso.

Esse trabalho apresentará informações relacionadas aos estudos realizados em torno de um teodolito pertencente à coleção de objetos de C\&T do MAST, destacando e detalhando o momento do restauro pelo qual passou entre 2002 em 2003. A partir dos resultados obtidos, caracteriza-se tal momento como decisivo para a sobrevivência do objeto e para sua contextualização junto ao público do museu.

O objeto

A partir de uma avaliação do estado de conservação dos objetos da coleção ${ }^{12}$, a seleção do objeto a ser estudado utilizou como critérios o estado geral de conservação e o potencial histórico da peça. Procurou-se, assim, escolher um instrumento com situação bastante comprometida, que justificasse o investimento para a restauração, e que apresentasse indícios históricos de sua relevância. A articulação desses dois aspectos propiciou a correlação entre os estudos de conservação e de construção da trajetória de objetos.

Para o estudo, foi escolhido um teodolito, de número de registro 1994/153. Esse instrumento foi fabricado por Brunner Frères, em Paris, na segunda metade do século XIX. Sua seleção levou em consideração os seguintes aspectos:

- O potencial histórico da peça, que pode ter sido utilizada em trabaIhos de pesquisa importantes, com participação do Observatório;

- O fabricante do instrumento, de reconhecida capacidade técnica;

- A deterioração das superfícies metálicas, bastante oxidadas, com perda de grande parte do verniz original;

- A falta de algumas partes do instrumento, que permitiria, no caso de optar-se pela restauração, exercitar uma das etapas mais críticas desse processo: a reposição de peças.

A Figura 1 apresenta imagem característica do instrumento selecionado; e as Figuras 2 e 3 apresentam detalhes de algumas de suas partes mais comprometidas.

O teodolito é um instrumento de geodesia - ciência que se relaciona com a determinação e o registro dos aspectos da superfície da Terra de forma acurada, permitindo a elaboração de mapas em escala -, utilizado para medir ângulos reduzidos no horizonte, distâncias zenitais ${ }^{13} \mathrm{e}_{\text {azimutes }}{ }^{14}$. Os instrumentos históricos de geodesia estão entre os mais coletados mundialmente e, nessa área da ciência, o teodolito e o nível são os objetos fundamentais. O grau de acurácia nas medidas geodésicas variou bastante desde a Antiguidade, quando medidas 


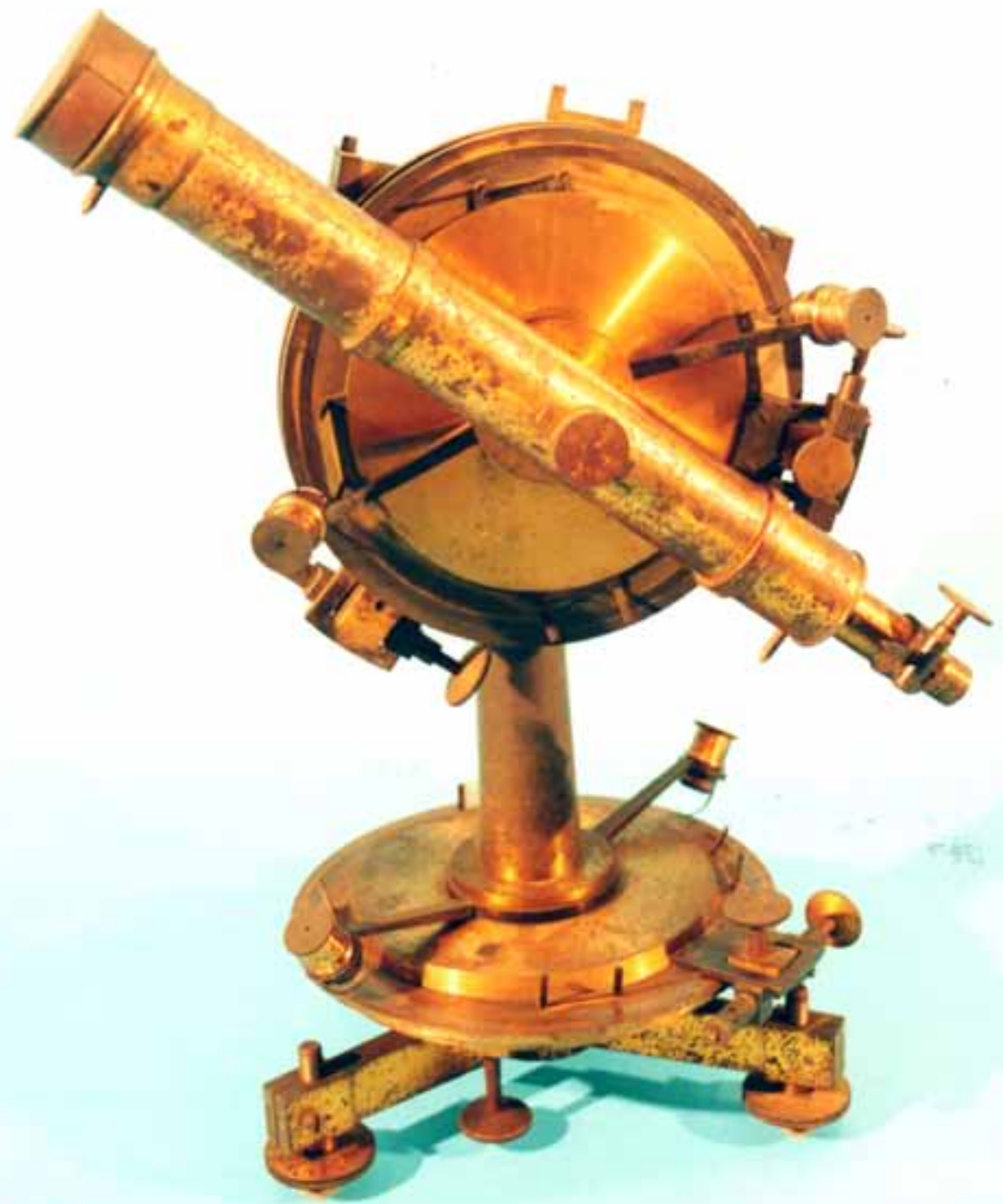

Figura 1 - Teodolito astronômico utilizado no estudo. Fotografia de Ricardo de Oliveira Dias, 2002. Acervo MAST, Rio de Janeiro. 


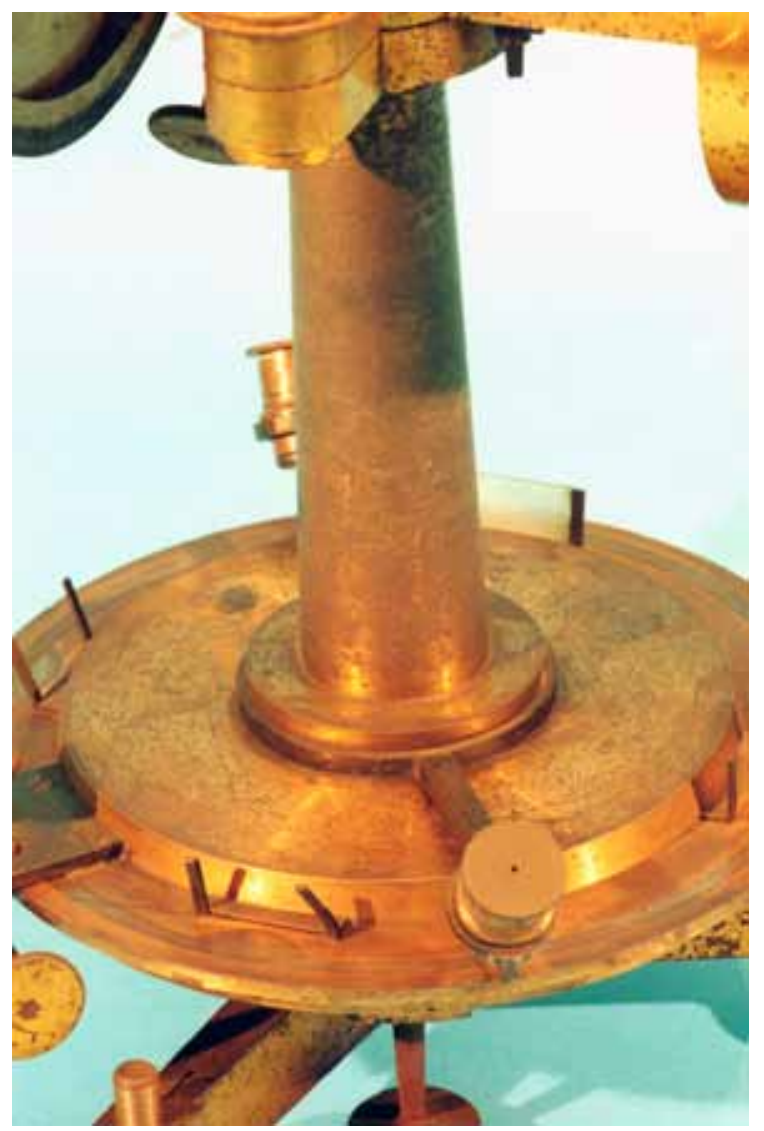

Figura 2 - Haste central do teodolito com superfície quase totalmente corroída e base onde alguns vidros de observação estão ausentes. Fotografia de Ricardo de Oliveira Dias, 2002. Acervo MAST, Rio de Janeiro.

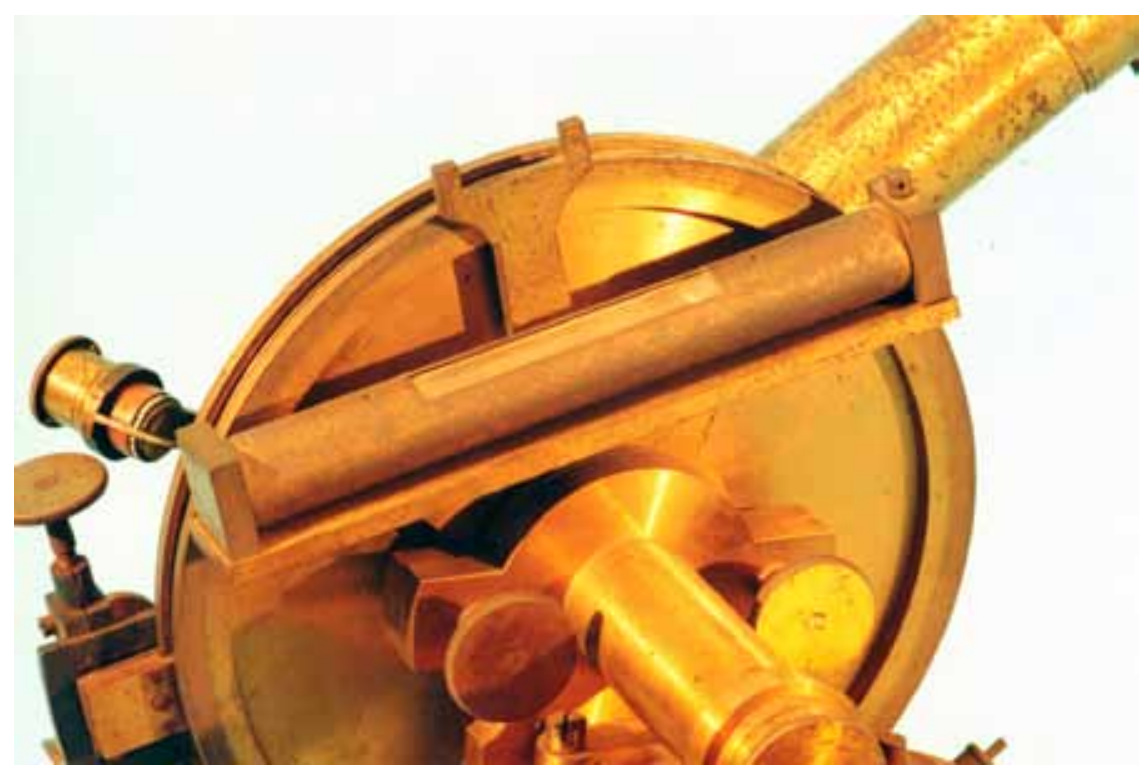

Figura 3 - Nível de bolha do teodolito bastante oxidado, destacando-se a ausência de nível de cavalete móvel. Fotografia de Ricardo de Oliveira Dias, 2002. Acervo MAST, Rio de Janeiro. 
aproximadas eram suficientes. A demanda pela precisão provocou a sofisticação crescente desses instrumentos.

A fim de atender a necessidades sociais cada vez mais complexas, surgiram instrumentos de geodesia, ampliando nossos sentidos e memória. Evidências sobre algum tipo de atividade relacionada remontam a 3000 a.C., quando as civilizações do Egito e da Babilônia precisaram dividir terras, construir sistemas de estradas e definir distâncias ${ }^{15}$. Suas evidências materiais mais antigas vêm da Mesopotâmia e do Egito Antigo, onde agrimensores trabalhavam nas planícies inundadas dos rios Tigre, Eufrates e Nilo, irrigando, medindo, registrando, e valorando terra agricultável ${ }^{16}$. Tinham função também na construção de monumentos, assegurando que as estruturas fossem eretas e devidamente alinhadas.

A compreensão da geometria e o uso de dispositivos mecânicos cordas de nós, prumos, círculos graduados e arcos setoriais, feitos em madeira, fibra e metal - caracterizaram a geodesia até o século XVI. A acurácia desses instrumentos aumentou no decorrer dos séculos, tendo sua utilização se tornado mais variada, ao mesmo tempo em que, muitas vezes, também sua ornamentação foi ficando mais valiosa.

A rejeição gradual do sistema de mundo de Ptolomeu e a aceitação do universo heliocêntrico de Copérnico foram causas indiretas do início, em torno do ano 1500, de uma nova era desse ramo da ciência. $\bigcirc$ catalisador das mudanças na instrumentação foi Galileu, utilizando lentes de vidro em seus telescópios de observação do céu ${ }^{17}$. Esse fato colocou a geodesia num curso que durou quase 500 anos. Teodolitos, níveis, taqueômetros, sextantes, câmeras fotogramétricas e outros instrumentos foram surgindo e evoluindo à medida que se desenvolveram as técnicas industriais de manufatura e os materiais optomecânicos.

$\operatorname{Jim} A$. Bennett analisou detalhadamente a evolução dos teodolitos nos séculos XVIII e XIX, mostrando as alterações que foram ocorrendo no projeto desse instrumento. Vale destacar a diferenciação entre teodolitos "planos" e de "trânsito", sendo os primeiros paulatinamente substituídos pelos últimos, à medida que $O$ século XIX avançava. O teodolito plano - fabricado no século XVIII, representado pelos fabricantes Simms \& Troughton, Ramsden e Simms - apresentava dois discos com 4 parafusos niveladores que fixavam o eixo vertical, que, por sua vez, suportava dois discos horizontais. A borda do disco inferior era dividida em 30 minutos; o disco superior carregava dois verniers para leituras de até um minuto. $\bigcirc$ disco superior suportava também uma bússola, dois níveis de bolha e dois suportes tipo A do eixo horizontal. $\bigcirc$ disco vertical, também com verniers, permitia leituras até a mesma precisão. $\bigcirc$ telescópio estava fixado nos suportes tipo $Y$, montados no topo do semicírculo vertical ${ }^{18}$.

teodolito de trânsito combinava aspectos do teodolito plano com o altazimute. $\bigcirc$ termo trânsito não está relacionado ao trânsito de estrelas, como a princípio pode parecer, mas indica que o telescópio do teodolito pode rotacionar em $180^{\circ}$ sobre o eixo, de forma a confrontar cada direção. $\bigcirc$ teodolito de trânsito surgiu em 1840 e, em 1868, já suplantava o teodolito plano ${ }^{19}$.
15. Ver Ronald Pearsall, (1974).

16. Ver Michael Cooper (2002).

17.Ver Henry C. King (1974).

18. Ver Jim Bennett (2000).

19. Ver James Clendinning (1966). 
20. Como as do Museo Galileo e da Fondazione Scienza e Tecnica (Firenze); do Musée des Arts e Métiers (Paris); do Boerhaave Museum (Leiden); do Science Museum e do National Maritime Museum (London); e as do Mast, do Observatório Nacional, e a Biblioteca Nacional, todas no Rio de Janeiro.

21. Todos disponíveis no Site da Universidade de Chicago: $<$ http://wwwcrl-jukebox uchicago.edu/bsd/bsd/ hartness/minopen.htm>; em: <http://brazil.crl.edu/ bsd/bsd/hartness/minopen html>. Acesso: 10 fev. 2011. QUAL DOS DOIS??
Por volta de 1950, iniciaram-se mudanças tecnológicas, trazendo para os instrumentos de Geodesia efeitos muito mais rápidos e amplos do que quaisquer outros anteriores. Iniciava-se, então, uma nova era nessa ciência. Embora componentes elétricos já tivessem sido incorporados várias décadas antes, somente em 1950 o advento da eletrônica, particularmente do transistor (e, mais tarde, dos circuitos integrados), trouxe a mais recente transformação dos instrumentos dessa área. Nos últimos anos, ocorreram mais transformações do que nos 7 mil anos anteriores.

Conhecendo o objeto

A pesquisa dos aspectos históricos relacionados ao objeto - que podem auxiliar na construção da trajetória do teodolito e são determinantes para as decisões a serem tomadas num processo de restauração - utilizou fontes diversas para obtenção de informações. Um amplo levantamento bibliográfico foi realizado em bibliotecas especializadas ${ }^{20}$,MAST sendo encontradas referências bibliográficas que sintetizavam grande número de informações de interesse para a pesquisa. Assim, as fontes foram bibliográficas, no que tange ao fabricante e ao funcionamento do instrumento, e à história do desenvolvimento técnico de instrumentos similares.

Em relação ao histórico de utilização do instrumento, foi realizado um levantamento de fontes primárias nos seguintes arquivos históricos: Arquivo Nacional; Arquivo Histórico do Ministério das Relações Exteriores (Palácio do Itamarati, Rio de Janeiro); Biblioteca Nacional (busca pelos relatórios das comissões de limites); Arquivo de História da Ciência do MAST, (fundos Observatório Nacional e Lélio Gama); relatórios de atividades do Ministério das Relações Exteriores, entre 1895 e 1900; do Ministério da Agricultura, entre 1860 e 1960; e do Ministério do Império, entre 1832 e $1888^{21}$.

\section{fabricante}

Entre os séculos XVII e XIX, os fabricantes de instrumentos científicos formavam um grupo seleto de artesãos orgulhosos de produzir instrumentos belos e funcionais. Mesmo com o rápido avanço tecnológico ocorrido durante o século XIX, continuaram a trabalhar da mesma forma artesanal, apesar de lançarem mão das novas máquinas e ferramentas que asseguraram escalas graduadas mais acuradas e instrumentos mais precisos.

Durante a segunda metade do século XIX, somente os melhores fabricantes europeus e americanos eram capazes de produzir os instrumentos de alta precisão necessários para medições acuradas em metrologia, geodesia e astronomia. Entre os fabricantes franceses da primeira década desse século Gambey e Lerebours eram sinônimos de excelência. Sua habilidade e capacidade foram posteriormente desenvolvidas por pessoas como os Brunners e Paul Gautier. 
Na segunda metade do século XIX, tornaram-se os representantes mais renomados da indústria francesa de precisão. Brunner e seus dois filhos especializaram-se em instrumentos de astronomia, de geodesia e topografia, enquanto o fabricante francês Gautier tornou-se o mais importante na área dos grandes instrumentos de astronomia.

Paolo Brenni publicou um trabalho apresentando a trajetória da família Brunner na fabricação de instrumentos científicos. Entre os fatos por ele destacados, as palavras da Comissão de Fabricantes Franceses de Instrumentos resumem o julgamento vigente sobre os objetos que foram exibidos pelos irmãos Brunner na exposição de Paris de 1867: "Pour la construction des instruments de précision, construction et fini, c'est la maison Brunner frères qui peut prendre le premier rang" 22

De fato, a qualidade e elegância de seus instrumentos, a precisão de suas escalas gravadas, e a exatidão de suas partes mecânicas representaram os padrões mais elevados da atividade francesa nessa área.

Johann Jakob Brunner (1769-1850) foi um respeitado serralheiro da vila suíça de Balsthal, no cantão de Solothurn. Um de seus filhos, Johann Josef Brunner (1804-1862), tornou-se um famoso fabricante de instrumentos em Paris. Em 1828, após passagem por Viena, mudou-se para Paris, onde ficou conhecido como Jean Brunner.

Provavelmente, abriu sua própria oficina em 1830 e, em 1839, participou pela primeira vez da Exposição Nacional Francesa, onde foi agraciado com a medalha de prata. Na exposição seguinte, em 1844, apresentou muitos instrumentos, como teodolitos, microscópios e bússolas magnéticas. Mas foi um círculo astronômico de $6 \mathrm{~cm}$ de diâmetro que mais impressionou o júri, determinando a outorga da medalha de ouro. $\bigcirc$ sucesso repetiu-se na exposição de 1849.

Em 1853, Jean Brunner tornou-se artiste adjoint do Bureau des Longitudes e, nesse mesmo ano, propôs à Académie um novo círculo meridiano, que foi utilizado pela Marinha francesa durante a expedição hidrográfica à llha de Guadalupe.

Pouco antes de sua morte, Jean Brunner participou da Exposição Universal de Londres (1862), expondo, além de vários instrumentos de topografia e de ótica, um círculo meridiano $(42 \mathrm{~cm})$ fabricado para o vice-rei do Egito. Tendo morrido no mesmo ano, seus filhos Émile (1834-1895) e Léon (1840-1894) continuaram suas atividades. $\bigcirc$ nome oficial da firma alterou-se para Brunner Frères, e os dois irmãos trabalharam seguindo a tradição de seu pai. Em 30 anos de atividades, continuaram a inventar, desenvolver e aprimorar instrumentos astronômicos de topografia e de geodesia.

instrumento selecionado para este estudo faz parte de um grupo de objetos fabricados pela mesma casa existentes no acervo do MAST. Três desses instrumentos foram fabricados por Jean Brunner, provavelmente entre 1830 lano da abertura de sua oficina) e 1862 (data de seu falecimento). Os demais foram 
23. Ver, no arquivo do Mast: OFÍCIOS recebidos, 7 maio 1900 (doc. 47); 2 jan. 1909 (doc. 322)

24. Ver, no arquivo do Mast: OFÍCIOS recebidos 1901/1904, 20 mar. 1903 (s./n.); no Arquivo do Palácio do Itamarati: [OFÍCIO do Imperial Observatório] 11 jan. 1909 (doc. 05 e doc. 180).

25. Ver, no arquivo do Mast: OFÍCIOS recebidos 2 . Semestre 1912, 28 set. 1912 (doc. 27); OFÍCIOS recebidos da Secretaria do Estado em 1912, 18 set. 1912 (doc. 3960)

26. Ver, no arquivo do Mast: OFÍCIOS remetidos 2. Trimestre 1916, 11 jul. 1916 (doc. 432).

27. Ver, no arquivo do Mast, OFÍCIOS recebidos 1894, 20 fev. 1894 (s./n.); no Arquivo Nacional: OBSERVATÓRIO Astronômico (14 out. 1878; 6 fev. 1879); no Arquivo do Palácio do Itamarati: [OFÍCIO do Imperial Observatório] 11 jan. 1909 (doc. 05-IO e doc. 180-MRE).

28. Ver, no arquivo do Mast: OFÍCIOS remetidos 2. Trimestre 1923, 2 abr. 1923 (doc. 130)

29. Ver Revista do Observatório Nacional (1890, p.97).

30.Ver Henrique Morize1906 fabricados no período de 1862 a 1895, data de encerramento das atividades da casa Brunner pelo falecimento do último dos irmãos.

\section{Aspectos históricos sobre o uso do teodolito}

O teodolito selecionado para o estudo de caso deve ter sido comprado entre 1865 e 1890 pelo Observatório, mas não foi encontrado qualquer testemunho documental que identificasse a data exata da compra e da chegada do instrumento ao Brasil. A documentação analisada até permite identificar essas datas para certos instrumentos, inclusive alguns dos provenientes da casa Brunner Frères, mas não é possível correlacionar ao instrumento específico estudado.

A leitura dos documentos que fazem referência a instrumentos do Observatório, pesquisados nos diversos arquivos históricos, permite constatar que a instituição emprestava com muita frequência esses objetos para outras repartições e instituições, tanto no período do Império quanto na República. As finalidades eram as mais diversas, variando desde a construção de estradas de ferro ${ }^{23}$, até a delimitação de fronteiras do Brasil com países vizinhos ${ }^{24}$, passando por estações meteorológicas ${ }^{25}$, e até a Repartição Geral dos Telégrafos ${ }^{26}$; diversos documentos apresentam trechos que permitem tal constatação.

Aparentemente, o Observatório funcionava muitas vezes como depósito de instrumentos, solicitados para utilização por outras instituições. Existem também alguns documentos mostrando haver no Observatório uma oficina que fazia reparos em instrumentos e, até mesmo, fabricava peças sob requisição de outras repartições ${ }^{27}$.

A coleção de instrumentos científicos do MAST, em sua maioria proveniente do Observatório, pode ser considerada uma das grandes coleções de seu gênero no mundo. Mesmo assim, a leitura dos documentos permitiu verificar que, no decorrer do tempo, muitos outros instrumentos foram perdidos, seja por terem sido inutilizados em seu uso, seja por não terem sido devolvidos ao Observatório, seja por terem sido doados para fins de ensino ${ }^{28}$.

Leituras de exemplares da Revista do Observatório Nacional permitiram identificar duas citações de trabalhos realizados com instrumentos fabricados por Brunner. Em 1890, fala-se de um círculo meridiano de Brunner (de n. 2), usado para medição das passagens meridianas em cada estação da E. F. Central do Brasil29. Também em Posição geográfica de Queluz e Ouro Preto ${ }^{30}$, trabalho de Henrique Morize publicado na Revista em 1906, fala-se do uso dos velhos círculos portáteis de Brunner na expedição para demarcar a posição geográfica dessas cidades. Documentos do arquivo Lélio Gama fazem referência à utilização de instrumento Brunner no Serviço de Latitude (estudos dos níveis), mas não especificam qual o objeto utilizado.

Quanto ao teodolito de Brunner Frères, que constitui o foco principal deste trabalho, é difícil, nos documentos, identificar dados que possibilitem a correlação direta com o objeto, pois são vagos em relação a detalhes que poderiam permitir tal identificação. 
As pesquisas realizadas permitiram relacionar uma série de informações a respeito de instrumentos científicos utilizados em comissões diversas, informações essas incorporadas ao banco de dados do registro museológico desses objetos. De tais comissões, foram selecionadas aquelas em que seja citado um teodolito e, especificamente, teodolitos Brunner, como apresentado a seguir:

- Carta Geral do Império ${ }^{31}$ - em 1875, em um ofício dessa comissão32, é citada a utilização de um teodolito de Brunner ${ }^{33}$.

- Comissão Astronômica da Secretaria de Estado dos Negocios da Agricultura, Commercio e Obras, 1876 a $1879^{34}$ - cita-se a utilização de 4 teodolitos topográficos de Brunner ${ }^{35}$ e de 1 teodolito de Brunner Frères 36

- Comissão de Olinda (Província de Pernambuco) ${ }^{37}$ - cita-se a utilização de um teodolito Brunner ${ }^{38}$ nessa comissão ${ }^{39}$.

- Comissão Punta Arenas-Estreito Magalhães ${ }^{40}$ - cita-se a utilização de um teodolito de Brunner nessa comissão chefiada por Luis Cruls, diretor interino do Imperial Observatório ${ }^{41}$.

- Comissão de Saneamento da Capital do Império 42 - foi encontrada citação sobre o uso de 2 teodolitos de Brunner n. $5^{43}$ em suas atividades $^{44}$.

- Comissão de Limites Brasil-Guiana Francesa ${ }^{45}$ - foi encontrada citação sobre o uso de um teodolito astronômico portátil Brunner Frères ${ }^{46} \mathrm{em}$ suas atividades ${ }^{47}$

As informações aqui apresentadas mostram que o teodolito estudado (ou instrumentos similares) foi utilizado em atividades historicamente importantes. Em alguns casos, o objeto é citado como teodolito Brunner e, em outros, como de Brunner Frères, e pode ser que estejam sendo relacionados instrumentos fabricados por Jean Brunner (Brunner) e por seus filhos (Brunner Frères); ou que, no momento da escrita, tenha sido colocado somente Brunner, mesmo tendo sido fabricado por Brunner Frères. Nada se pode assegurar a respeito.

Após esse período em que o Observatório participou com seus instrumentos para diversas expedições científicas e técnicas ou emprestou-os, incluídas aí várias comissões de limites, não se têm informações documentadas sobre possíveis atividades em que poderiam ter participado instrumentos como o teodolito de Brunner Frères em estudo. Pouco se sabe sobre esse objeto - e outros tantos do acervo do Museu que, do período após a mudança para o Morro de São Januário na década de 1920, sobreviveram até nossos dias.

que teria acontecido a ele a partir do momento em que não foi mais utilizado? Permaneceu encaixotado? Ficou esquecido em uma sala até ser redescoberto no âmbito do recém-criado Museu de Astronomia em 1985? Nesse período, a documentação existente é falha, e nenhum vestígio foi encontrado até o momento.
31. Comissão formada em 1865 para levantar, organizar e elaborar a carta geral do império, prevista para 42 folhas, mostrando os mapas das regiões, os limites das províncias e do império com os países vizinhos. Várias foram as expedições e os serviços de topografia necessários para a sua realização.

32. Ver, no arquivo do Mast: OFÍCIOS recebidos, 1875 .

33. Nesse ano foi elaborada a nova Carta Geral do Império (escala 1:3.710.220) pelos artistas Henshel \& Benque, por processo fotolitográfico. O teodolito foi utilizado no âmbito desse projeto.

34. Comissão formada em 11 de fevereiro de 1876 pelo Imperial Observatório do Rio de Janeiro e encerrada em fevereiro de 1879. Sua criação está relacionada ao prolongamento da estrada de ferro Santos-Rio Claro e sua implantação.Aproveitando a necessidade de determinar as posições geográficas para a estrada de ferro, foi criada uma comissão de engenheiros e astrônomos para a concomitante realização de um vasto estudo científico. Cf Brasil (1876-1, p. 339); Brasil (1876-2, p. 152-158), no site da University of Chicago.

35. Ver, no arquivo do Mast: OFÍCIOS recebidos, 28 jun. 1879a (Doc. 1/1).

36. Ver, no arquivo do Mast: OFÍCIOS recebidos, 28 jun. $1879 \mathrm{~b}$ (s./n.).

37. Uma das três comissões instituídas pelo Imperial Observatório do Rio de Janeiro para observação da passagem de Vênus pelo disco solar em 6 de dezembrode 1882. As outras duas foram a Punta Arenas-Estreito de Magalhães e a Ilha de S.Thomaz (Antilhas), todas organizadas durante a gestão interina de Luis Cruls no Imperial Observatório. 
38. Ver, no arquivo do Mast: Luis Cruls (1882a)

39. Cf., no site da University of Chicago: Brasil (1883, p.70).

40. Ver, no arquivo do Mast: Luis Cruls (1882b).

41. Cf. Brasil (1883, p.70), no site da University of Chicago.

42. Comissão organizada em 14 de agosto de 1886, pelo Ministério do Império, visando ao melhoramento sanitário da capital do Império, chefiada pelo engenheiro J. J. Levy.

43. Ver, no arquivo do Mast: OFÍCIOS recebidos, 18 out. 1886 (doc. 9/1).

44. Os trabalhos da comissão começaram pelo saneamento da lagoa Rodrigo de Freitas, pela drenagem profunda do solo da cidade e pelos estudos relativos ao melhoramento do canal do Mangue.

45. Comissão estabelecida em 1900, pelo Ministério das Relações Exteriores, para definição dos limites com a Guiana Francesa.

46. Ver, no arquivo do Mast: OFÍCIOS recebidos, 19 maio 1900 (doc. 3).

47. Cf. Brasil (1900, p. 4), no site da University of Chicago.

48. Nas instituições: Fondazione Scienza e Tecnica, Firenze, em 2000; e Maritime Museum, London, em 2003.

49. Como, por exemplo, do Science Museum (London), Boerhaave Museum (Leiden), Opficio delle Pietre Dure (Firenze), Museo di Storia della Scienza (Firenze), Musée des Arts e Métiers (Paris), Museum of the History of Science (Oxford), Direction des Musées de France (Paris)

50. Ver Jean-Pierre Mohen (1999).

51. Ver Mara Miniati e Paolo Brenni (1993).
A restauração do objeto

Com base na bibliografia consultada, em estágios realizados ${ }^{48}$, e em diferentes discussões mantidas com profissionais de diversas instituições da área de restauro 49 foi possível verificar que, nos últimos anos, tem variado a abordagem em relação ao restauro de instrumentos científicos históricos, seja nas diferentes instituições ou até mesmo dentro de uma mesma instituição, mas, aparentemente, sua evolução sempre ocorreu no sentido do princípio da mínima intervenção.

Não mais se orienta pela busca do funcionamento do instrumento, mas pela preservação de sua estrutura e evidências históricas, de forma a permitir o contato das gerações futuras com essas peças. $O$ aspecto do funcionamento tem sido resolvido, no caso de peças especiais, com a utilização de modelos e réplicas que permitem manter objetos similares em contato com o público. Em situações singulares, um instrumento de valor histórico poderá ser colocado em funcionamento, desde que o custo-benefício justifique tal utilização e que esse contato possa fornecer informações e conhecimentos que permitam compreender um pouco mais do momento histórico a que esses objetos estão relacionados.

Outros autores também abordaram o problema do fazer funcionar instrumentos pertencentes a acervos museológicos, entre eles Jean-Pierre Mohen ${ }^{50}$, em relação aos museus de técnica e de música. Segundo o autor, essas instituições seriam confrontadas com a tentação de restituir a função inicial dos objetos como um relógio que volte a marcar as horas ou um violão para ser tocado num concerto. E conclui que seria ilusório reencontrar as condições autênticas de experimentação desses objetos (por exemplo, os instrumentos musicais medievais) na recriação de músicas antigas, pois eles já seriam outros, com anos de alterações físicas, e outros também os músicos que os tocariam e a própria audiência, que seriam atuais. $\bigcirc$ passado não se recria.

O primeiro momento no processo de restauração de um objeto é o questionamento sobre a validade de realizá-lo, por ser essa uma atividade cara e trabalhosa. Mara Miniati e Paolo Brenni discutem esse ponto com muita propriedade e apontam a raridade, a antiguidade, a complexidade e a origem da peça como possíveis critérios de decisão. No entanto, ressaltam que o mesmo aparelho, em âmbito diverso, pode assumir também significados diferentes ${ }^{51}$. Por exemplo, uma máquina eletrostática, produzida aos milhares e muito comum ao fim do século XIX, pode ser objeto de uma longa intervenção de restauro quando faz parte de uma coleção homogênea e completa de aparelhos desse século, porque o descuido com esse exemplar criará um vazio nessa coleção.

Seguindo os preceitos e a experiência adquiridos nos processos acima descritos, estipulou-se uma metodologia de restauração a ser utilizada para o teodolito aqui apresentado. As etapas constituintes do processo de restauro foram: desmontagem das peças, conservação de algumas peças, restauração de boa parte das peças, substituição de algumas peças ausentes. 
Os objetivos principais da etapa de desmontagem do instrumento selecionado foram os seguintes:

- separar peças para análise em microscópio eletrônico de varredura;

- produzir réplicas metalográficas em algumas peças para análise das estruturas;

- avaliar o processo de desmontagem e coletar informações sobre o instrumento por observação visual, ;

- avaliar o estado de conservação do objeto mais detalhadamente; e

- proceder à conservação das partes que exigissem tal procedimento.

A desmontagem caracteriza-se por ser uma etapa básica do processo de conservação de instrumentos científicos, como preconizado por Suzanne Keene:

Mesmo a ação aparentemente inocente de desmontagem do instrumento para limpeza e remontagem pode causar danos. Por exemplo, na remoção de parafusos, onde cada um foi especialmente feito para o seu buraco. É essencial registrar a posição de cada um quando desmontando o objeto. A fenda do parafuso é específica exigindo a utilização de uma chave que sirva exatamente ao tamanho da cabeça do parafuso, de outro modo o parafuso pode ser entortado e a superfície do instrumento danificada ${ }^{52}$.

Assim, todo o processo de desmontagem seguiu um protocolo estrito, com etiquetagem das peças, registros escritos e fotográficos, de forma a não comprometer a etapa final de remontagem do instrumento (Figura 4).

A análise do instrumento permitiu verificar que foram realizadas algumas intervenções anteriores. Observando a luneta do teodolito, comparando com os desenhos esquemáticos do instrumento ${ }^{53}$ e com um outro teodolito similar existente na coleção, verificou-se que foram realizadas duas adaptações a posteriori da fabricação, não sendo, portanto, partes originais do instrumento. A primeira foi a introdução de duas hastes metálicas, em forma de ponteira, sendo uma próxima à lente objetiva e outra na extremidade oposta do tubo da luneta. As duas ponteiras estavam alinhadas e parafusadas no tubo de luneta. Observaram-se resquícios de pintura em cor branca nessas partes.

A segunda intervenção foi a introdução - na extremidade próxima à lente ocular e imediatamente conjugada ao parafuso de ajuste do foco da ocular - de uma peça em formato de mira, com regulagem por parafusos.

Verificou-se também que a tampa da luneta provavelmente não é a original, pois o material parece ser diverso do restante do instrumento, de cor avermelhada, mais parecido com um bronze e possuindo, na parte interna, soldas que estão fora do padrão de qualidade do restante da peça. A tampa estava 


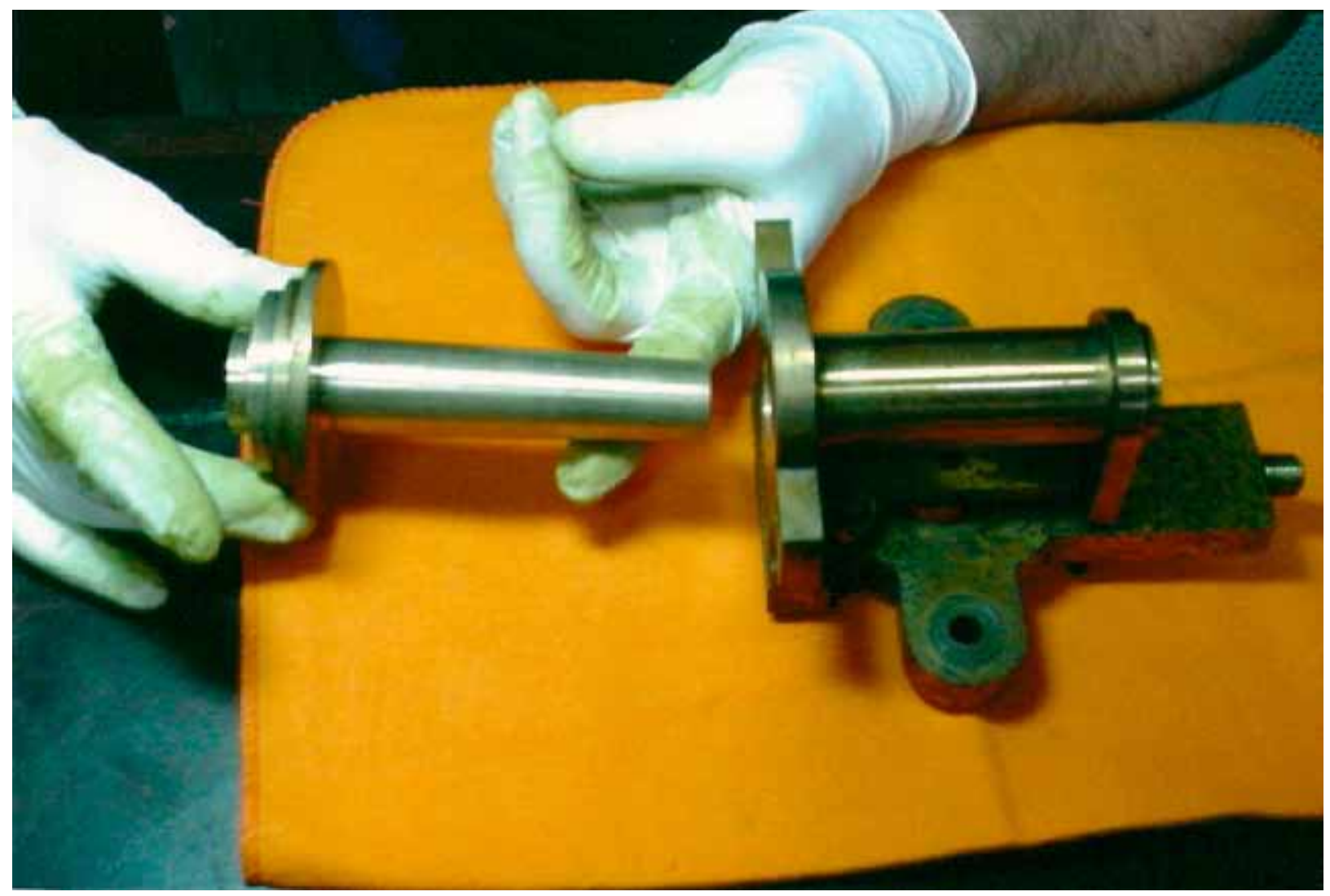

Figura 4 - Imagem de uma das etapas da desmontagem do instrumento, mais especificamente das peças do eixo do círculo vertical. Fotografia de Marcus Granato, 2002. Acervo MAST, Rio de Janeiro.

coberta por uma camada depositada especialmente para proteção da peça e não deve ser tratada.

Durante o processo de desmontagem e avaliação das peças, verificouse nelas a presença de algumas marcas. A avaliação, com lente de aumento, do círculo horizontal permitiu descobrir a inscrição do fabricante:

$$
\text { Brunner } F^{\text {res }} \text { à Paris } N \text { o } 1
$$

A inscrição mostra que o instrumento foi fabricado em Paris, por Brunner Frères e que se trata do teodolito de número 1. Por outro lado, em diversas oportunidades, foram encontrados números marcados em peças do instrumento. No círculo vertical e em diversas outras peças da parte superior do objeto encontrou-se o número 5. Examinando o outro teodolito da coleção, que é igual ao de estudo, verificou-se que o número marcado em suas peças é o número 6 . Conclui-se que o teodolito em estudo é composto por várias partes que não são originais do teodolito Brunner Frères № 1. Portanto, depreende-se que o teodolito de número 1 poder ter sido intensivamente utilizado e, por conta disso, algumas partes foram danificadas, determinando que um outro teodolito idêntico fosse 
"canibalizado", o de número 5, para reposição das peças necessárias. Outra conclusão possível é que foram enviados, talvez no mesmo lote, pelo menos seis teodolitos iguais ao estudado.

A Figura 5 apresenta uma imagem com detalhe de inscrição em peça do teodolito, indicando que pertencia ao teodolito de número 5 e não àquele em processo de restauração (de número 1).

A observação visual do instrumento e a análise de suas partes permitiram verificar que estão ausentes o nível de cavalete, as lentes objetiva e ocular, e dois vidros despolidos, utilizados como anteparo para observação dos valores na leitura dos círculos graduados. As lentes e o cavalete são partes

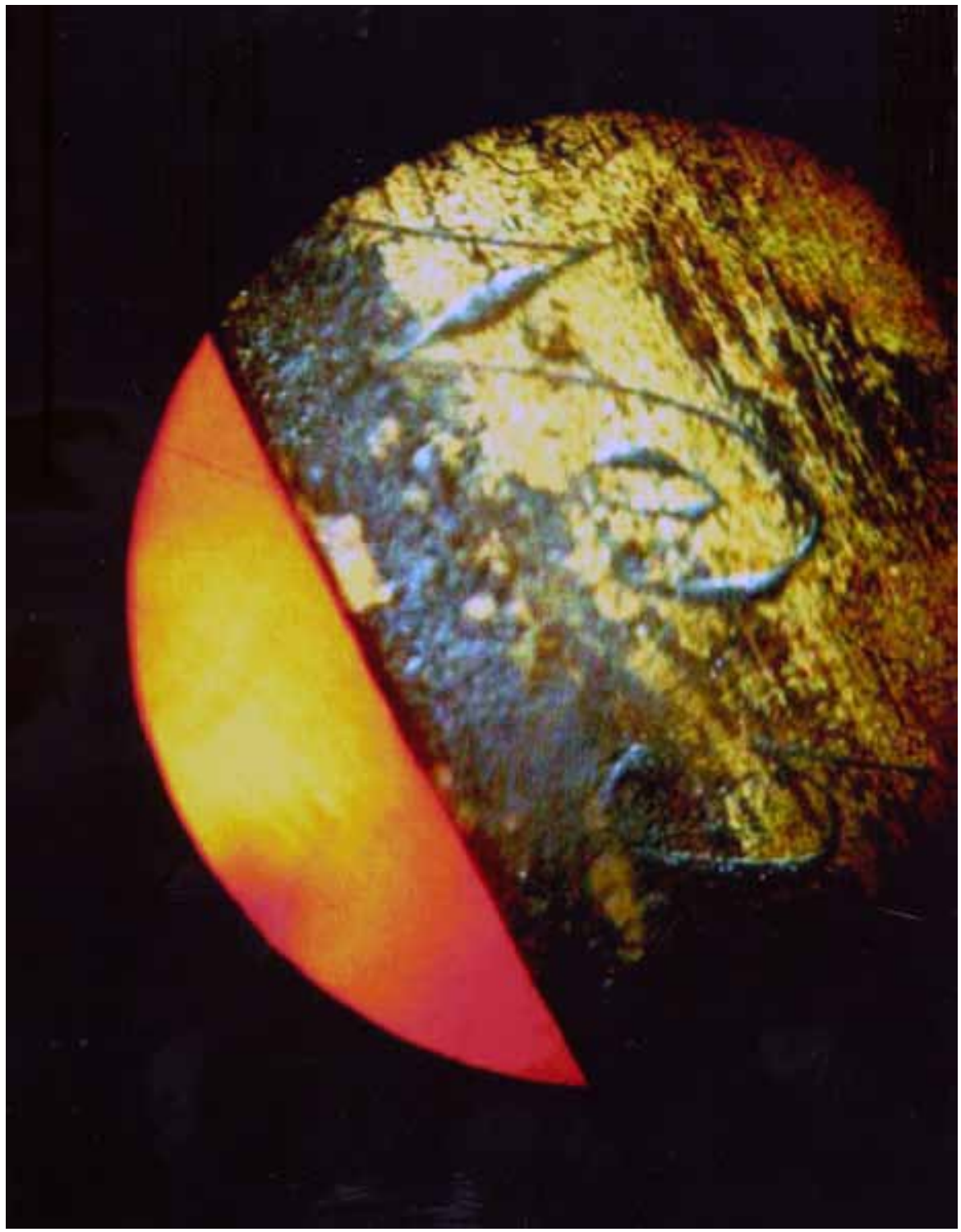

Figura 5 - Imagem com detalhe de inscrição em peça do teodolito, indicando que pertencia ao teodolito de número 5 e não àquele em processo de restauração (de número 1). Fotografia de Ricardo de Oliveira Dias, 2002. Acervo MAST, Rio de Janeiro. 
54. O microscópio eletrônico de varredura (MEV) utilizado foi um LEO S440, equipado com sistema de análise química pontual por Espectrometria de Dispersão de Energia (EDS), modelo Link ISIS L300 com detetor de SiLi Pentafet, janela ultrafina ATW II, com resolução de $133 \mathrm{eV}$ para $5,9 \mathrm{keV}$ e resolução espacial de $1 \mu \mathrm{m}$ a $2 \mu \mathrm{m}$ de área e $1,5 \mu \mathrm{m}$ a $5 \mu \mathrm{m}$ de profundidade, dependendo das características do feixe e da densidade da fase analisada. integrantes, e sua ausência compromete a integridade do objeto, pois sem eles não é possível considerar o instrumento completo e há prejuízo irreversível de seu funcionamento.

Devido à corrosão, várias peças do objeto encontravam-se em diversos estados de comprometimento. O pior estado de conservação estava nas partes relacionadas com a manipulação do instrumento para seu uso, como a haste central e a luneta, sendo que a haste perdera praticamente toda a cobertura de verniz. Também a superfície do nível de bolha fixo no instrumento estava bastante oxidada, mas a câmera de vidro preservara-se, assim como o líquido em seu interior. Havia corrosão pontual em toda a superfície do contrapeso, apesar de estar preservado o verniz. O círculo horizontal estava bastante danificado, mas o vertical bem conservado, com o verniz protetor mantido.

O nível de bolha fixo encontrado no teodolito não é o original, já que o formato é ligeiramente diferente daquele identificado em desenhos originais do instrumento. Apesar de suas dimensões serem iguais às da peça original, verificaram-se diferenças na comparação com o nível existente no teodolito (número de registro 1994/154), idêntico ao do instrumento em estudo. Os parafusos existentes na face inferior do suporte do nível não estavam faceando a superfície, indicando não serem os parafusos originais de fixação da peça. Uma análise mais atenta, com lupa, mostrou que o tubo de vidro do nível também é diferente daquele do teodolito 1994/154. A peça original deve ter sido danificada durante o uso e descartada, sendo substituída por outra similar. $\bigcirc$ estado das superfícies (bastante deterioradas) dessa peça sobressalente mostrou, também, que ela deve ter sido bastante manuseada, ação a que um nível fixo não deveria ser submetido.

Apesar de não ser mais original, esse nível será mantido no objeto, pelo fato de fazer parte de sua história, tendo sido substituído enquanto o instrumento ainda estava em uso. Será realizado, no entanto, um registro, na ficha do instrumento, identificando essa peça como de substituição.

\section{Aspectos da composição das peças do teodolito}

Para conhecer a composição metálica do objeto selecionado, foram utilizadas duas técnicas não destrutivas: a análise por microscopia eletrônica de varredura $(M E V)^{54}$, utilizando a técnica de espectrometria de dispersão de energia (EDS); e a análise de microestrutura por microscopia ótica, através da técnica de metalografia. Neste último caso, foram produzidas réplicas metalográficas de superfícies selecionadas para a análise. As peças do instrumento analisadas com a primeira técnica foram diferentes das analisadas com a segunda, já que as limitações de cada técnica, nas dimensões da amostra a ser analisada, não o permitiam.

As imagens microscópicas produzidas no MEV foram geradas por detector de elétrons retroespalhados (BSD), que produz níveis de coloração cinza proporcionais ao peso atômico médio do material analisado; assim, quanto maior o seu peso atômico, mais claras as fases aparecem na imagem. Não houve 
recobrimento das amostras, o feixe operou em $20 \mathrm{kV}$ e a corrente do filamento foi de $1200 p A^{55}$.

A seleção das peças para análise teve por critérios as dimensões dos objetos, em vista da limitação da câmara do MEV $(9,0 \mathrm{~cm} \times 4,0 \mathrm{~cm})$ e a localização das peças - se na superfície externa do instrumento ou como componente interno.

A observação da microestrutura das demais peças selecionadas foi realizada através de réplicas metalográficas, pois apresentavam dimensões incompatíveis com a câmara do MEV. As réplicas foram produzidas no MAST e as observações realizadas por microscópio ótico no laboratório do Programa de Engenharia Metalúrgica e de Materiais (Coppe-UFRJ).

Os resultados detalhados das diversas análises realizadas, assim como a discussão a seu respeito, podem ser encontrados em tese de doutoramento mencionada neste trabalho ${ }^{56}$.

De forma sucinta, a caracterização dos materiais constituintes do objeto mostrou que o latão $\alpha(\mathrm{Cu}=68,7 \pm 0,8 ; \mathrm{Zn}=31,3 \pm 0,8)$ era o componente predominante, seguido do bronze em fases $\alpha$ e $\varepsilon$ (composição média geral da liga: $84,6 \%$ de cobre, 3,7\% de zinco e 11,7\% de estanho); em menor grau, aparecem a prata (usada nas escalas) e o aço da alma da coluna principal do instrumento e de partes de alguns parafusos.

Plano de intervenção

Após a desmontagem do instrumento, as partes foram avaliadas segundo a necessidade específica de intervenção. Algumas peças dispensam qualquer procedimento; outras pedem uma limpeza superficial, que denominaremos conservação; outras ainda necessitariam de intervenções mais profundas, às quais denominaremos restauração; e, finalmente, estavam faltando algumas peças no instrumento, determinando uma avaliação das possibilidades de substituição por réplicas. Em princípio, todas as peças deveriam ser limpas para posterior continuidade do processo.

As peças que não exigiam intervenção foram apenas limpas da poeira depositada. Aquelas que necessitavam conservação foram limpas com uma cera de proteção específica, muito utilizada por museus europeus, cuja composição é: cera micro-cristalina (100g), cera de polietileno $(25 \mathrm{~g})$ e aguarrás (250ml). As partes envernizadas não foram enceradas, visto que a camada de verniz poderia ser comprometida.

Peças que foram restauradas, em que havia resquícios de verniz, foram limpas com solução de cloreto de metileno, para sua remoção. Em seguida, foram lavadas com água em abundância, para retirada da solução removedora anterior, e secas. Utilizando processos mecânicos - pastas de polimento, lixas de granulometria fina -, as partes oxidadas foram tratadas para eliminar as camadas de produtos de oxidação. Nos casos de corrosão pontual, por pite ou localizada em áreas específicas que não justificavam o tratamento da superfície total da peça, também foi utilizado o bisturi.
55. Ver As análises foram gentilmente realizadas no Laboratório de Caracterização Tecnológica, situado no Setor de Caracterização Tecnológica e Ambiental (SCT) do Centro de Tecnologia Mineral (Cetem/MCT).

56. Ver Marcus Granato (2003). 
Para eliminação das camadas de produtos de corrosão das peças produzidas em torno mecânico, que originalmente possuíam marcas circulares de fabricação, foi dado tratamento no torno, de forma a restabelecer os círculos característicos.

Após a eliminação dos produtos de corrosão, as peças sem verniz foram limpas com solução (tricloroetileno) para remover gorduras e em seguida protegidas por uma camada da cera (já citada). Todas as peças tratadas que possuíam proteção por camada de verniz passaram por uma fase final, que constou de remoção de gorduras (tricloroetileno) e aplicação posterior e imediata de nova camada de verniz. Após a aplicação do verniz, a peça foi levemente aquecida em estufa $\left(60^{\circ} \mathrm{C}\right)$ para acelerar a polimerização da resina. $O$ verniz utilizado foi similar, em composição, ao empregado nos instrumentos desse período histórico.

Quanto às peças ausentes, foi avaliada a possibilidade de sua reprodução exata. Caso isso fosse possível, as réplicas produzidas seriam marcadas de forma a permitir sua fácil identificação. Os materiais utilizados na fabricação foram os mais próximos possíveis dos originais, mas permitindo sua identificação como réplicas.

\section{Restauração do teodolito}

\section{Conservação de Peças}

A primeira peça a ser tratada foi o círculo horizontal, tendo sido higienizado utilizando-se algodão e óleo fino (mamona). A parte inferior da peça necessitou apenas de limpeza e a escala de prata foi tratada observando-se em lupa, para assegurar que as marcas da escala não fossem danificadas (Figura 6).

A parte de latão contígua à escala, onde se situa a marca do fabricante, estava escurecida por camada de oxidação superficial, que foi retirada na limpeza. A parte superior da base do círculo apresentava-se bem conservada, com exceção de uma área em um dos cantos do disco. Na base do disco inferior, identificaramse algumas áreas com oxidação superficial, que foram apenas limpas.

Todas as peças do círculo horizontal foram limpas seguindo o mesmo procedimento (algodão e óleo). O sistema de chamada desse círculo, o suporte do disco, a alma da coluna central de latão, os microscópios do círculo horizontal e seus suportes exigiram apenas limpeza geral. Por outro lado, o tripé de sustentação, o disco superior do círculo, algumas faces dos parafusos niveladores, os parafusos de fixação do círculo e a coluna central exigiram o restauro.

A base do círculo vertical apresentou o círculo mais externo, contíguo à escala de prata, coberto por camada de sujeira ressecada, provavelmente de graxa, que foi retirada com o auxílio de bisturi e lupa, para não danificar a superfície da peça. Após retirada a camada de sujeira, descobriu-se o número 5 marcado no círculo, determinando a descoberta de mais uma parte que não é original do teodolito de número 1, aqui estudado. 


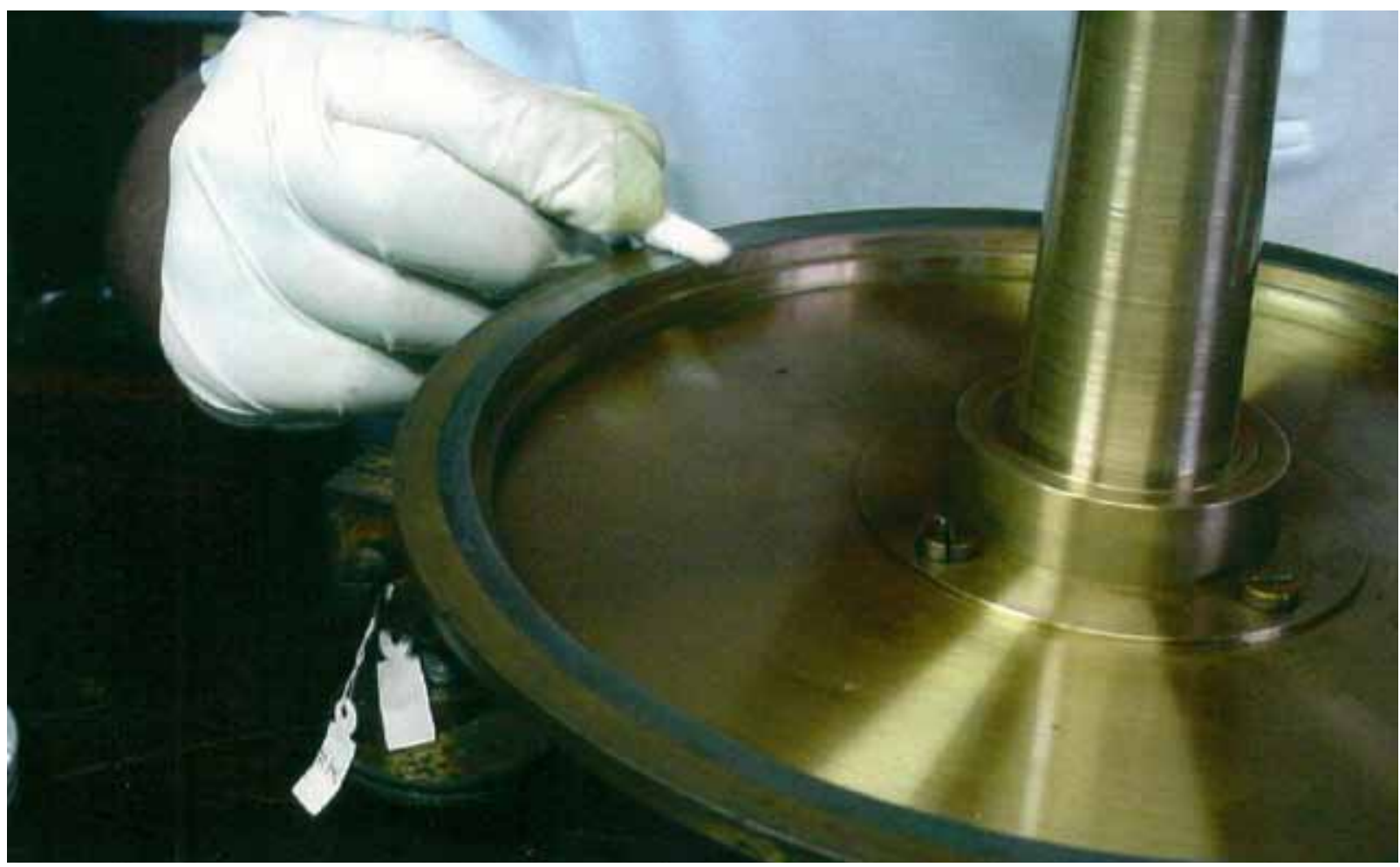

Figura 6 - Higienização da base do círculo horizontal do teodolito. Fotografia de Marcus Granato, 2003. Acervo MAST, Rio de Janeiro.

eixo de aço do sistema do círculo vertical estava plenamente preservado, exigindo apenas uma limpeza superficial. Uma peça do suporte desse eixo apresentou, em uma das faces, uma camada marrom fosca, ali colocada propositalmente, não podendo ser eliminada no processo de limpeza.

\section{Restauração de Peças}

A primeira etapa do restauro consistiu em retirar a camada de produtos de corrosão existente na superfície das peças selecionadas. Foram priorizados os processos mecânicos em detrimento dos químicos. As peças de formato circular (originalmente torneadas) foram tratadas em torno mecânico, na oficina mecânica do Cetem; as demais foram trabalhadas no laboratório de conservação do MAST.

Constavam do primeiro grupo de peças selecionadas: o círculo horizontal, a coluna central de sustentação, o contrapeso, o parafuso de freio do círculo horizontal, e dois parafusos recartilhados. A primeira a ser trabalhada foi a coluna central.

estado da coluna era lamentável: apresentava-se completamente coberta de produtos de corrosão e sem traços de verniz protetor. Para sua melhor fixação ao torno, foi confeccionada uma peça em alumínio acompanhando o formato cônico da base da coluna. Assim, os mordentes de fixação do torno não 
foram ajustados à peça do teodolito e, sim, à de alumínio, não causando quaisquer danos à peça original (Figura 7).

Para o acabamento final, foram empregadas lixas 320 e 400 . Lixas mais finas $(600,720)$ não foram utilizadas, para não produzir uma superfície muito brilhante, resultado muito diverso do acabamento utilizado em peças desse tipo. Durante o procedimento, a superfície do suporte era limpa, periodicamente, com algodão, para retirada da suspensão de óleo com produtos de oxidação.

A técnica adotada possibilitou a reprodução das linhas de fabricação da peça, condição importante a ser alcançada num processo de restauro desse tipo. Uma peça ainda não restaurada, em amarelo mais forte, precisou ser trabalhada manualmente, em vista de seu formato impedir o uso do torno mecânico. A cor da coluna, bem amarelada, confirma a composição indicada pelo processo de caracterização, sendo realmente um latão.

O círculo horizontal, peça seguinte a ser tratada, teve sua intervenção realizada fixando-se o círculo na coluna suporte, que já havia sido tratada, de forma a possibilitar a utilização da já citada peça de alumínio como base de fixação do conjunto no torno mecânico.

O procedimento utilizado no disco horizontal foi o mesmo descrito anteriormente e sua cor, ligeiramente avermelhada, confirma a composição indicada como sendo um bronze ao caracterizá-la. O círculo mais externo, em

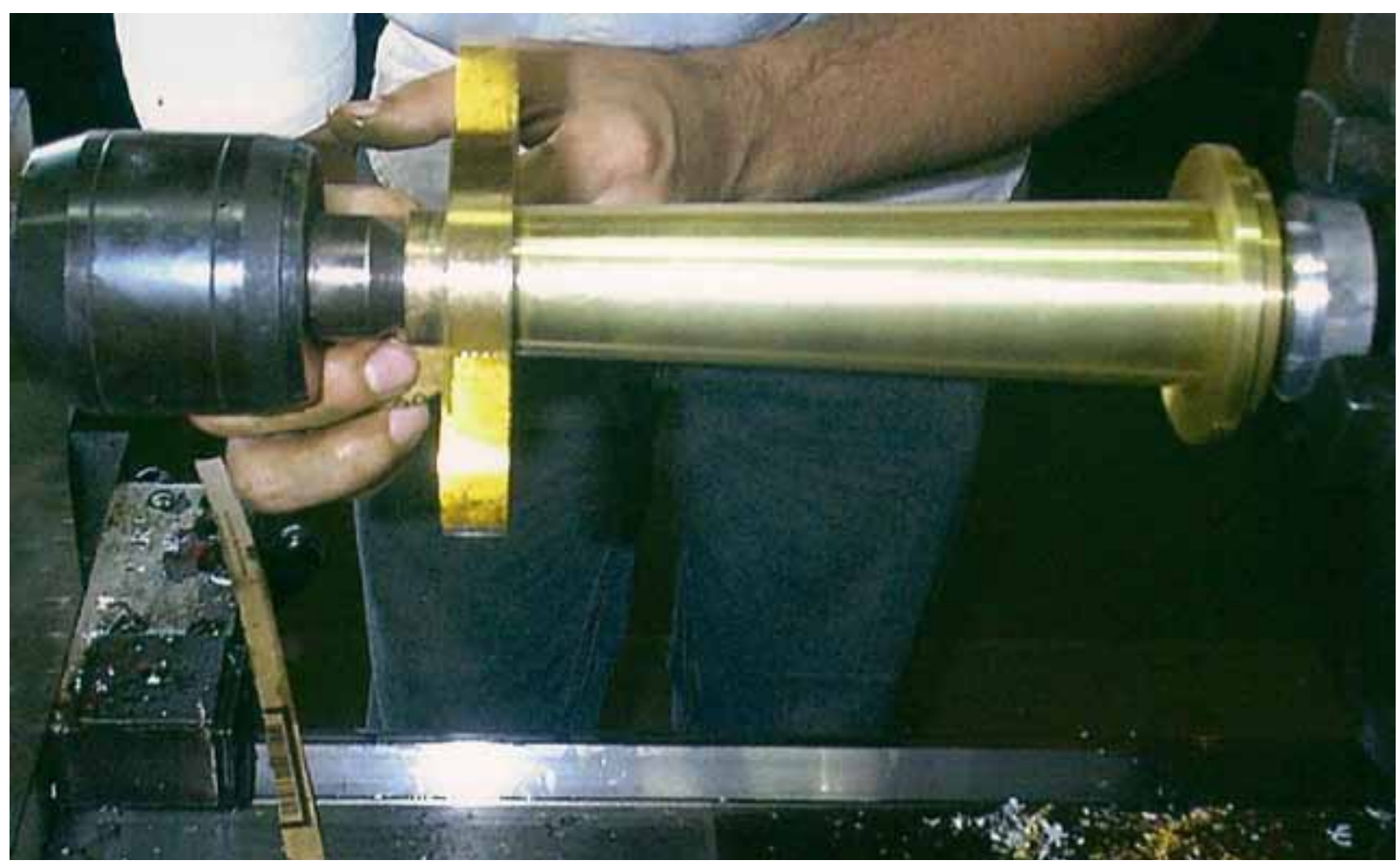

Figura 7 - Coluna central de sustentação do teodolito, fixada no torno mecânico para o restauro. Fotografia de Marcus Granato, 2003. Acervo MAST, Rio de Janeiro. 
nível mais baixo que o do restante da peça, não foi trabalhado no torno para não danificar as escalas de prata existentes em cada pólo da peça.

A próxima peça a ser restaurada foi o contrapeso, utilizando-se uma fita de alumínio em torno da peça para impedir danos durante a fixação no torno mecânico. $\bigcirc$ trabalho foi feito em duas etapas, invertendo-se a extremidade de fixação da peça para possibilitar o tratamento total da mesma. A Figura 8 apresenta uma imagem da peça sendo restaurada.

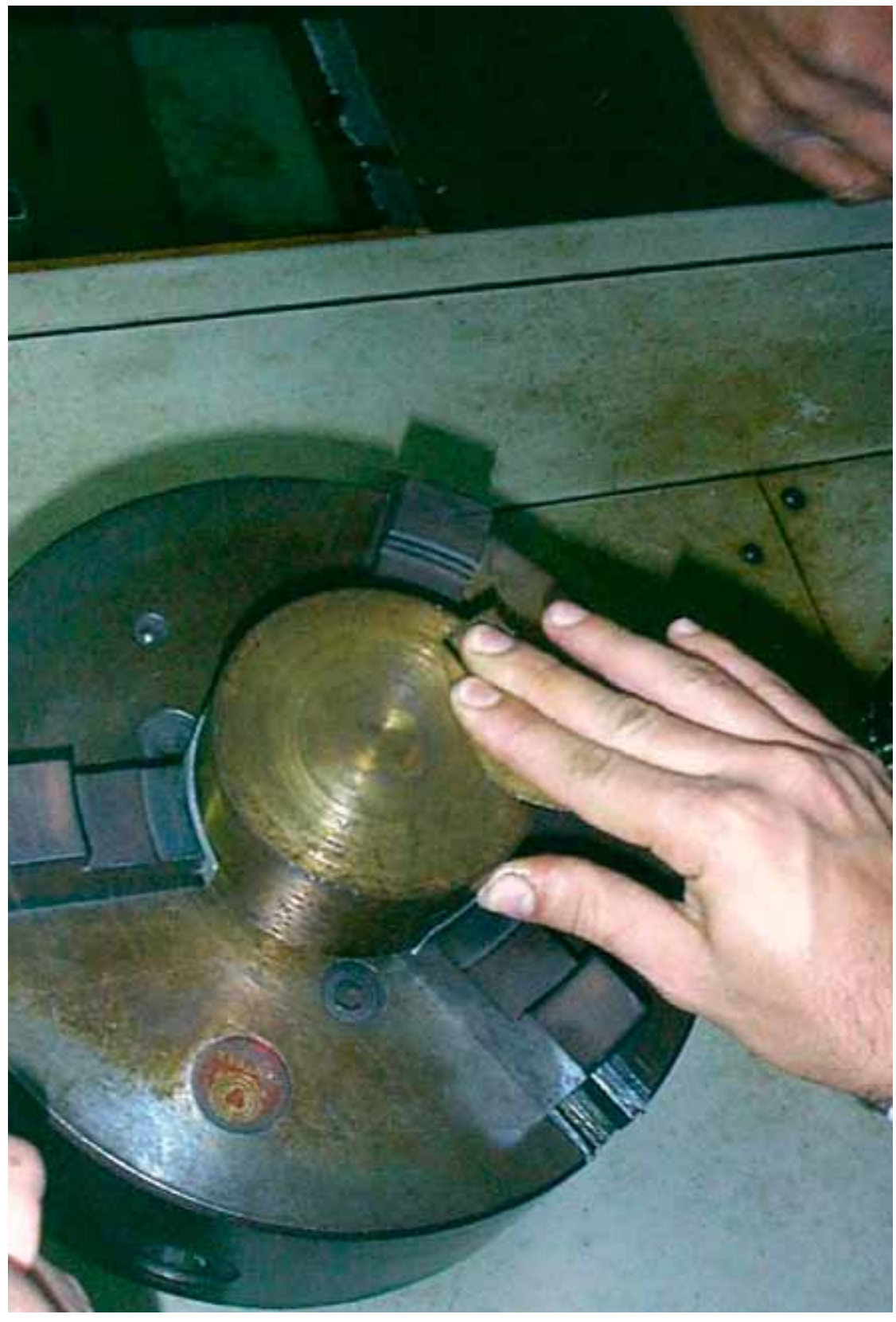

Figura 8 - Contrapeso do teodolito fixado ao torno, para trabalhos de restauro da peça. Fotografia de Marcus Granato, 2003. Acervo MAST, Rio de Janeiro. 
tratamento dos parafusos recartilhados foi iniciado pela fixação ao torno e, para evitar danos ao recartilhamento, utilizou-se um suporte rosqueado ao parafuso. O procedimento de remoção da camada de oxidação foi o mesmo já citado. Cada parafuso foi trabalhado de forma similar, produzindo o mesmo aspecto final; para evitar danos, o recartilhamento não foi tratado.

A finalização do procedimento para o primeiro grupo de peças ocorreu com o parafuso de freio do círculo horizontal. Para evitar danos durante sua fixação no torno mecânico, utilizou-se uma fita de alumínio em torno da parte rosqueada do parafuso. Após o tratamento, verificou-se que a cabeça do parafuso era constituída de latão, apresentando cor amarelada característica, e que a base do parafuso, antes da parte rosqueada, era constituída de aço, apresentando cor prateada acinzentada típica.

tratamento realizado no segundo grupo de peças separado para restauro foi o mesmo descrito anteriormente, destacando-se as seguintes observações:

- tubo de luneta - após a intervenção, a peça apresentou cor amarelada, típica do latão, confirmando as conclusões da etapa de caracterização. Para não desgastar o metal original, e foi descoberto um número 5, marcado na peça, mostrando que o tubo também pertencia ao teodolito de número 5;

- tubo do nível de bolha - mesmo procedimento, utilizando uma fita de alumínio para proteção da superfície e tratamento de $2 / 3$ do tubo, para posterior inversão e tratamento do restante;

- haste cônica do círculo vertical - somente a face mais externa foi tratada, pois a haste central propriamente dita é constituída de aço e estava em boas condições,

- dois parafusos do mordente do círculo vertical, 2 parafusos da haste que posiciona o nível fixo, 1 parafuso de ajuste do microscópio do círculo vertical, 1 parafuso de ajuste da ocular, e o suporte da lente ocular da luneta - tratados de maneira similar; destaca-se que o suporte da ocular é constituído de bronze;

- dois microscópios do círculo vertical - exceto a parte rosqueada, as peças foram tratadas, utilizando-se peça de PVC para a montagem, a fim de evitar danos pela fixação ao torno mecânico;

- tampa do visor da luneta - foi necessário montá-la numa peça de PVC para impedir danos à sua superfície.

$\bigcirc$ tripé do instrumento foi tratado manualmente, pois as linhas de fabricação precisavam ser respeitadas e utilizar o torno não era a melhor escolha de intervenção. Nas faces da peça, o lixamento foi realizado de forma diferenciada, dependendo da haste do tripé. A direção de passagem da lixa foi sempre centrípeta, mas, em duas das hastes, sem alcançar a área central. Para isolamento dessa área, foi utilizada uma fita adesiva sobre ela. Já a terceira haste 
apresentava linhas que se prolongavam por toda a extensão da parte central e, assim, fez-se o tratamento para remover a camada de produtos de corrosão. As partes laterais foram tratadas verticalmente, acompanhando a espessura da peça (Figura 9).

último grupo de peças separado para a remoção da camada de produtos de corrosão foi constituído dos três parafusos de nivelamento que suportam o tripé de base do teodolito e mais dois parafusos recartilhados. As intervenções seguiram os mesmos procedimentos antes utilizados e já descritos.

Após a etapa em que as camadas de produtos de corrosão foram eliminadas, todas as peças foram limpas com álcool absoluto e desengorduradas com tricloroetileno, sendo em seguida aplicada a solução de verniz ${ }^{57}$ nas peças originalmente protegidas dessa forma. Essa etapa final foi dividida em duas fases:

- a primeira consistiv em espalhar o verniz sobre a superfície metálica a ser protegida, de forma a produzir uma camada uniforme e sem defeitos. Para tal, foram utilizados apetrechos os mais diversos lespátulas, hastes de madeira, pincéis, suportes diferentes, chumaços de algodão de formatos variados etc.), pois cada peça exigiu uma abordagem diferente, relacionada diretamente ao seu formato.
57. O verniz foi produzido nos laboratórios do Cetem, segundo formulação proposta por Paolo Brenni. Separaram-se os compostos a serem utilizados na preparação em dois grupos, sendo o primeiro referente à produção de resina protetora e o segundo aos pigmentos que dão $o$ tom final do verniz; ver Paolo Brenni (1986). Os produtos do Grupo I são resinas naturais.As quantidades utilizadas de cada material foram: Grupo I - goma-laca (40g), goma-sandaraca $(80 \mathrm{~g})$ e mástique $(12,8 \mathrm{~g})$; Grupo II - sangue de dragão $(4,8 \mathrm{~g})$, goma-guta $(9,6 \mathrm{~g})$ e açafrão $(0,37 \mathrm{~g})$.

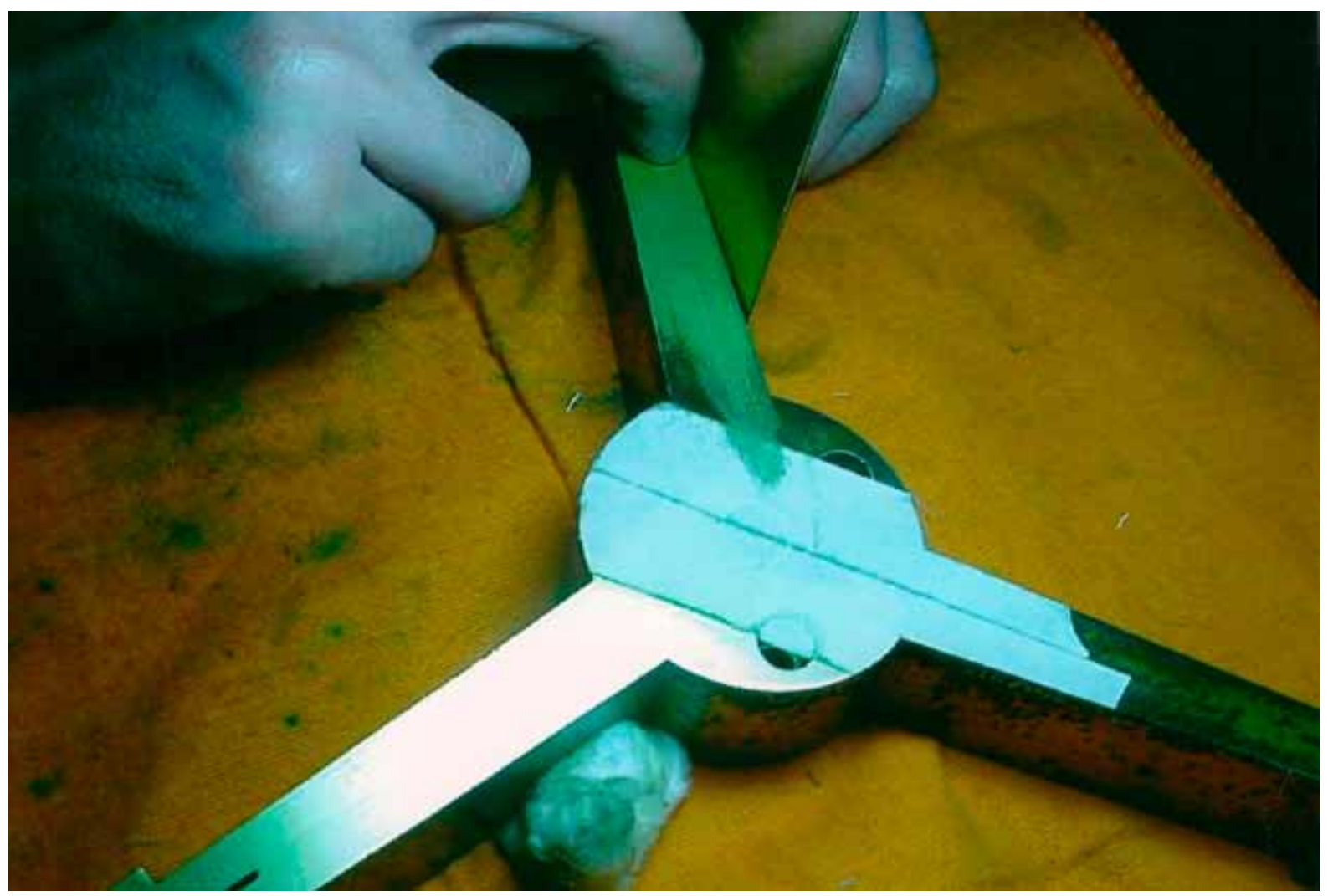

Figura 9 - Imagem da remoção de forma manual, das camadas de produtos de corrosão do tripé de sustentação do teodolito. Fotografia de Marcus Granato, 2003. Acervo MAST, Rio de Janeiro. 
- a segunda, realizada imediatamente após a primeira, consistiv em colocar a peça em uma estufa por 5 a 10 minutos, à temperatura entre $60^{\circ} \mathrm{C}$ e $80^{\circ} \mathrm{C}$, de forma a permitir a cura do verniz para a produção do acabamento final desejado.

É importante assinalar que, durante a aplicação de verniz no contrapeso, foi constatada uma linha muito fina, acompanhando internamente a borda circular, que pode ser identificada na lupa como sendo a marca que se relaciona com o núcleo de chumbo que deve existir nessa peça, já que seu peso supera em muito o do bronze puro.

Algumas vezes, na mesma peça, foram necessárias várias técnicas de aplicação, como, por exemplo, no caso da coluna central de sustentação do instrumento. A parte central, de formato cônico, foi sustentada por uma haste de madeira colocada através da passagem central da coluna, o que permitiu girar a peça e viabilizar a passagem uniforme do algodão embebido na solução de verniz. Já a parte situada na extremidade superior foi envernizada tendo a peça apoiada em uma superfície.

A Figura 10 apresenta: (a) imagem da aplicação do verniz; e (b) etapa posterior de aquecimento da peça na estufa.

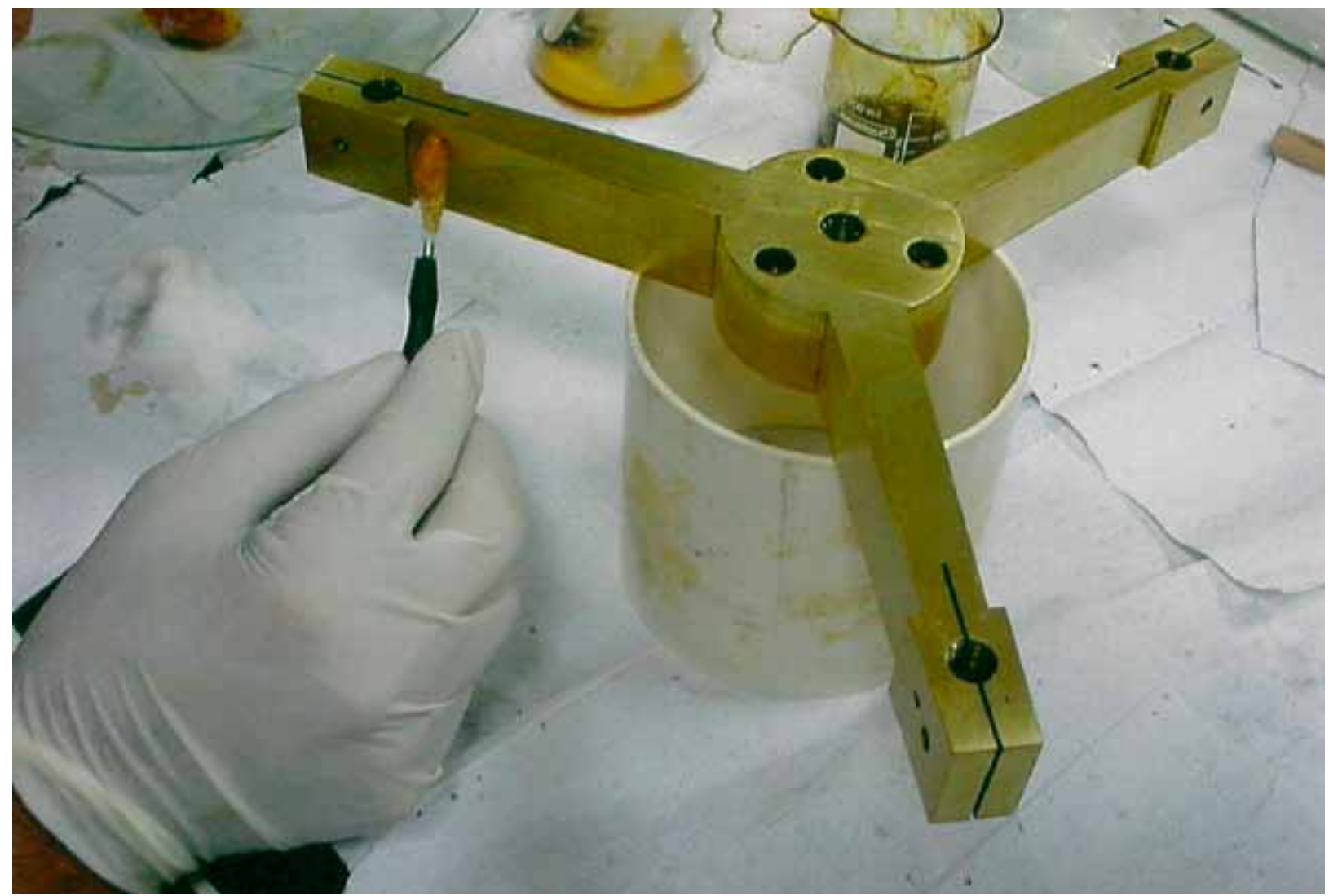

Figura 10 - Imagens do envernizamento do tripé de sustentação do instrumento (a) e da cura da coluna central, na estufa (b), após envernizamento. Fotografia de Ricardo de Oliveira Dias, 2003. Acervo MAST, Rio de Janeiro. 
A aplicação de verniz nas peças não alcançou todos os resultados desejados. Em todas as peças, foi possível utilizar o verniz produzido segundo a composição original, permitindo assim protegê-las contra a corrosão. A aplicação manual caracterizou-se por ser artesanal, quase artística, dependendo inteiramente da habilidade de quem a realizava. No entanto, a cor obtida não foi similar àquela das peças originais do instrumento, sendo bem mais clara. Por outro lado cabe ressaltar que os vernizes constituídos de componentes orgânicos apresentam um fenômeno de envelhecimento, que muitas vezes traz, com o tempo, o escurecimento da camada de proteção ${ }^{58}$. Assim, decidiu-se que a cor a ser utilizada seria uma intermediária entre o amarelo claro obtido com a receita original e o dourado escuro existente nas peças preservadas do instrumento.

Inicialmente, procurou-se seguir as instruções de G. Biraud, que indicavam ser determinante, para a coloração final do verniz, a temperatura de secagem na estufa, variando de amarelo claro $\left(60^{\circ} \mathrm{C}\right)$ até dourado escuro $\left(88^{\circ} \mathrm{C}\right)^{59}$. Tal não aconteceu. Mesmo ampliando o tempo de secagem até uma hora, não se observou qualquer variação na cor final. Assim, foi realizada uma pesquisa em laboratório para alcançar a cor desejada. Isso ocorreu com mistura, em diferentes proporções, no verniz originalmente produzido, de soluções concentradas das resinas sangue de dragão (vermelha, 60g/l) e goma-guta (amarela, $100 \mathrm{~g} / \mathrm{l}$ ).

Os melhores resultados de coloração foram alcançados utilizando uma mistura contendo quatro partes do verniz original, duas partes da solução amarela e uma parte da solução vermelha. Essas soluções, antes de serem utilizadas, permaneceram três dias em descanso, sendo depois filtradas para eliminar quaisquer partículas sólidas em suspensão. Com esse novo verniz, foram realizadas inúmeras tentativas de obter camadas homogêneas na superfície metálica. Pelas características intrínsecas da aplicação, relacionadas a uma técnica quase perdida, foi muito difícil obter a qualidade desejada. Brenni e colaboradores discutem o problema e indicam a utilização de aerógrafos ou spray para obter mais facilmente a qualidade desejada 60 . Muitos testes foram realizados tentando a utilização de dois modelos de aerógrafos nacionais, mas sem o sucesso esperado. A qualidade do acabamento obtido com esses equipamentos sempre deixou a desejar.

Foram então realizadas experiências com outros apetrechos, na tentativa de aperfeiçoar a aplicação, assim como contatos com pintores que forneceram informações que facilitaram a aplicação. Segundo os especialistas europeus do setor, essa habilidade se adquire depois de muito tempo de experiência e constitui etapa muito difícil e longa no treinamento de um restaurador $^{61}$. Acreditamos que a utilização de aerógrafos importados, que produzam um spray de melhor qualidade, poderá eliminar a técnica manual de aplicação. 
62. Cf. Paolo Brenni (1999, p. 93); tradução livre do autor.

63. Ver Françoise Le Guet Tully e colaboradores (1998).

64.Ver José Cândido Guilhobel (1879).

\section{Substituição de Peças Ausentes}

Paolo Brenni apresenta com clareza um caminho interessante para o caso das peças perdidas:

Em muitos casos faz-se necessário substituir peças perdidas e quando estamos certos do estado original do instrumento podemos proceder à sua reconstrução ou inserir réplicas das peças que faltam. Não compartilhamos com as ideias sobre materiais antigos de não tocar a "poeira do tempo", que na maioria das vezes é apenas sujeira, contentando-se em conservar uma relíquia de pouca utilidade ${ }^{62}$.

A avaliação inicial realizada no instrumento identificou a ausência de três peças importantes no objeto: a lente ocular, a lente objetiva e o nível de cavalete. Também faltavam dois vidros jateados, empregados na leitura das medidas de ângulos.

No Observatório de Nice, defrontando-se com o mesmo problema, Tully e colaboradores decidiram não refazer as partes que faltavam, e aquelas em funcionamento foram assim mantidas dessa forma[? ? $]^{63}$.

Aqui, decidiu-se que as peças consideradas fundamentais para a integridade do objeto deveriam, se possível, ser replicadas. Para tal, seria necessário ter o projeto detalhado de tais peças ou identificar um instrumento igual que as possuísse. Felizmente, a coleção possui um outro teodolito (1994/0154) igual a esse, em que constam duas lentes idênticas às que deveriam estar no objeto de estudo. Quanto ao nível de cavalete, também nesse outro instrumento ele está ausente. Mas, em referência bibliográfica da época de fabricação do teodolito, foi possível verificar o desenho detalhado do instrumento e identificar suas formas e dimensões exatas ${ }^{64}$.

A experiência de especialistas desse setor mostra que, dentro de uma coleção, muitas vezes as peças de um mesmo instrumento estão dispersas e até catalogadas como se independentes fossem. Assim, a primeira providência para verificar a existência de tais peças foi uma "caça ao tesouro", dentro da própria coleção. Verificou-se haver sete níveis de cavalete, bastante diferentes entre si em forma e dimensões. Essas peças foram separadas e analisadas à luz do próprio instrumento e da possível adaptação a seu locus nele; e, também, à luz da figura detalhada do instrumento, obtida na fonte bibliográfica citada. De todos os níveis avaliados, somente um apresentou-se como real candidato para continuidade dos estudos de identificação, o de número 1994/0254. Procedeu-se então a uma análise tanto de dimensões como de projeto do nível, e do aspecto geral da peça.

Verificou-se serem iguais as dimensões existentes no desenho e as medidas da peça selecionada. Mesmo o projeto era idêntico ao do desenho e do mesmo estilo do nível fixado ao instrumento. Observando o aspecto externo, também a cor - resultante do material utilizado na confecção da peça e do verniz de proteção - é idêntica àquela predominante no objeto como um todo. Além disso, havia áreas da superfície com processos de corrosão e essas áreas eram 
predominantes em um lado da peça, que corresponde, quando montada no instrumento escolhido para restauro, ao mesmo lado em que esse se apresenta mais comprometido por processos de corrosão. Pode-se afirmar, assim, que o nível de cavalete encontrado faz parte de um instrumento como aquele de interesse desse estudo.

Em princípio, não seria possível afirmar de forma peremptória que a peça é do instrumento em questão, pois existe um outro teodolito igual na coleção e nele também falta o nível de cavalete. Há, entretanto, indícios materiais muito fortes de que essa peça pertence a esse instrumento, principalmente por coincidir a predominância de áreas de corrosão em um dos lados da peça e em seu locus correspondente no instrumento. A leitura do objeto e a comparação entre os dois teodolitos iguais permitiram afirmar, no entanto, que esse comportamento das áreas de corrosão é adequado somente ao instrumento em estudo, permitindo afirmar que a peça pertence a ele.

Em face do constatado, não foi necessário produzir qualquer réplica do nível de cavalete. Quanto às lentes ocular e objetiva, procedeu-se ao mesmo expediente. Na coleção, foram identificadas nove lentes objetivas e dezessete oculares. Como as lentes do teodolito 1994/0154 são idênticas às que deveriam estar presentes no 1994/0153 (mas não estavam), bastou comparar as lentes existentes na coleção com as do instrumento citado para verificar que nenhuma das lentes testadas adequava-se ao teodolito em análise. Uma delas até se parecia com a lente objetiva original, mas uma diferença de $2 \mathrm{~mm}$ na largura eliminou tal possibilidade. Ou seja, as lentes originais do instrumento não foram encontradas.

A alternativa foi tentar obter as informações técnicas desejadas a partir das lentes do teodolito que se encontra na coleção e é igual ao objeto de interesse desse estudo. Separadas as lentes, tentou-se determinar sua composição, o índice de refração do vidro componente, e seus parâmetros óticos, mas tal não foi possível, pois, para as medições necessárias, seria necessário desmontar as lentes de seus suportes metálicos. As tentativas de desmontagem foram sempre infrutíferas e, para viabilizar as medidas, seria necessário destruir os suportes, algo injustificável. Essas peças não foram então replicadas.

Os vidros despolidos foram fabricados a partir de lâmina de vidro tipo pyrex, com espessura de $1 \mathrm{~mm}$, como a original. $\bigcirc$ tipo de vidro foi escolhido por ser o único disponível no mercado com a espessura desejada. A lâmina foi submetida a um processo de jateamento com óxido de alumínio lgranulometria 320\#) para obtenção da superfície despolida. Em seguida, as placas foram cortadas, com caneta de diamante, nas dimensões necessárias e, finalmente, marcadas com verniz para sua identificação como réplicas. Após ter sido feita a montagem completa do instrumento, essas réplicas foram aí colocadas.

A restauração na trajetória do instrumento

resultado final alcançado na restauração (Figura 11) permitiu preservar o instrumento selecionado e obter-se, no decorrer do processo, uma série de informações valiosas. A experiência aí desenvolvida possibilitou refletir sobre 


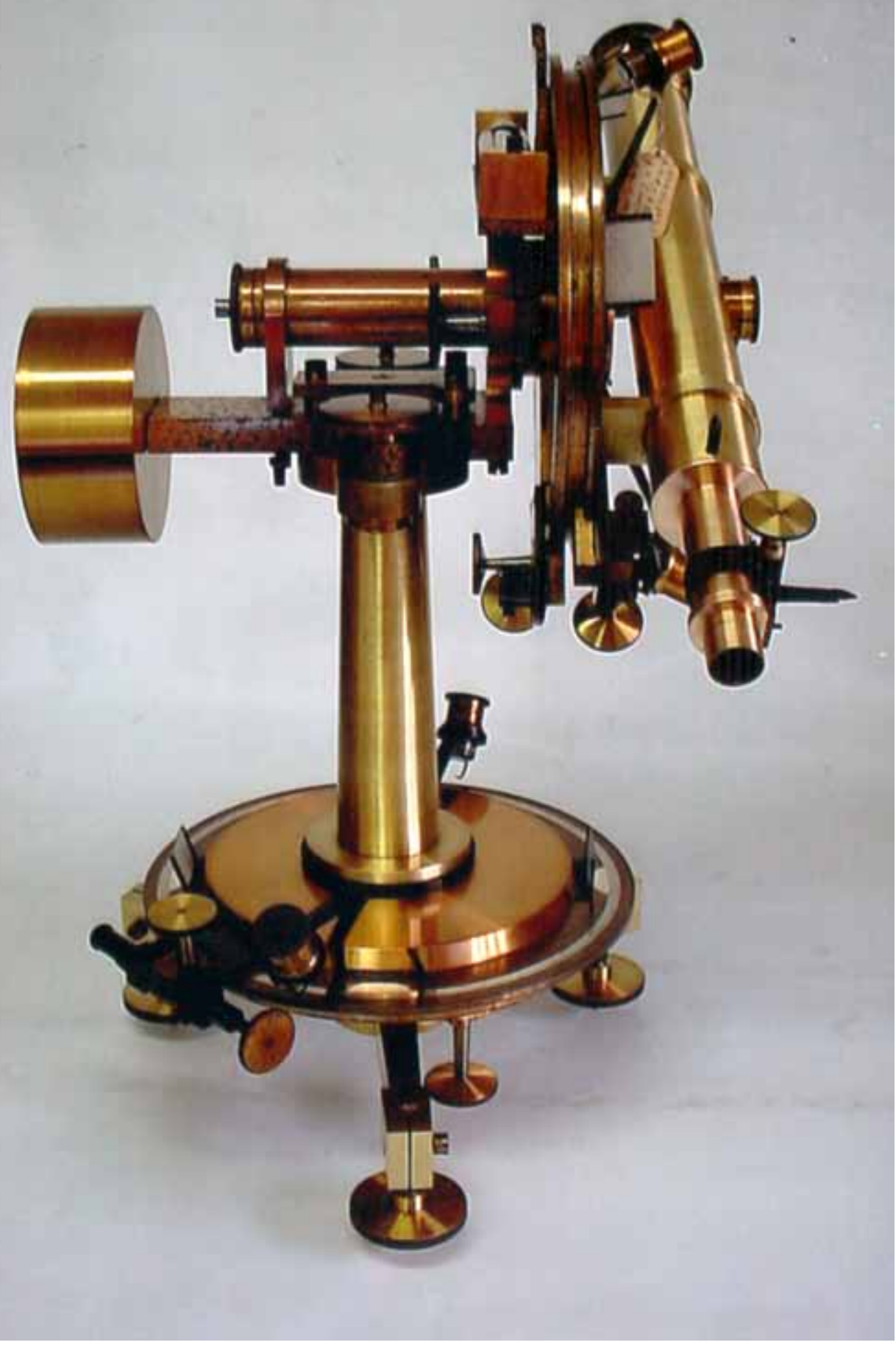

Figura 11 - Teodolito restaurado. Fotografia de Ricardo de Oliveira Dias, 2003. Acervo MAST, Rio de Janeiro. 
a própria vida do objeto. Os estudos acerca da história e da composição das peças do teodolito propiciaram um enriquecimento de detalhes de sua identidade e de sua trajetória de existência.

A partir dos dados colhidos, verifica-se, ao compará-los com resultados provenientes da construção de trajetórias de outros instrumentos e de seus conjuntos $^{65}$, que a restauração constitui etapa ímpar na trajetória de qualquer objeto cultural. É um momento em que profissionais de formação diversificada se aproximam do artefato e, com seu olhar diferenciado, percebem-no e produzem amplo espectro de informações.

Por outro lado, entretanto, intervenções inadequadas - aqueles casos em que a restauração não segue preceitos científicos nem a ética que orienta uma prática responsável - podem resultar em danos definitivos no objeto e mesmo na perda de suas características originais. E o prejuízo no que diz respeito à perda de conteúdo documental pode ser desastroso e provocar, inclusive, a perda definitiva de seu valor cultural.

É preceito reconhecido internacionalmente há décadas que todo procedimento de restauração deve sempre ser documentado da melhor forma possível. Aqui, reafirmamos a importância dessa orientação, pois a experiência da pesquisa para construção da trajetória de objetos ou de seus conjuntos amplia a importância dessa atitude.

Ao documentarmos um procedimento de restauro não estamos apenas registrando informações que possibilitem uma futura intervenção sobre o mesmo objeto: estamos trazendo à tona uma infinidade de novas informações, que ampliam significativamente o conhecimento sobre o objeto e, assim, seu potencial cultural e de comunicação. Facilita-se, em resumo, o trabalho do pesquisador que pretenda construir a sua trajetória e dos profissionais de museus que buscam uma aproximação maior entre o objeto e o público que é, certamente, em última análise, o detentor dos acervos culturais.

Esse aspecto vem ao encontro da teoria contemporânea da conservação, proposta por Salvador M. Víñas, onde o interesse primário está nos sujeitos e não mais nos objetos. A objetividade na conservação, fundamento da abordagem científica prevalente a partir do final do século XX, seria substituída por uma forma de subjetivismo66.

Nessa "teoria contemporânea", a noção de verdade é substituída por aquela de comunicação. A "verdade" deixa de ser o critério orientador da conservação e de sua legitimidade. Essa seria feita em função dos significados atribuídos ao objeto, significados esses que, segundo o mesmo autor, podem variar tremendamente de grupo a grupo. A conservação seria realizada para essas pessoas para as quais o objeto tem significado. Portanto, no processo de decisão, seus interesses (necessidades, preferências, e prioridades) deveriam ser considerados como o fator mais importante. Sua autoridade derivaria não de seu nível educacional, mas de serem diretamente afetados pelas ações que outros realizam em objetos que thes são significativos.
65. Ver Maria Alice C. de Oliveira (2011); e Janaina L. Furtado (2009).

66. Ver Salvador M. Víñas (2005). 
$\bigcirc$ estudo aqui apresentado sobre o restauro de um teodolito da coleção do MAST conduziu a algumas conclusões. Na história da ciência e da técnica no Brasil, foi possível relacionar uma série de eventos importantes em que foram utilizados teodolitos fabricados pela Casa Brunner. Pelas condições em que se encontrava o objeto de estudo desse trabalho, é possível afirmar que foi muito utilizado e que, provavelmente, participou de vários dos eventos citados. Verificouse também que foi enviado ao Observatório um grupo de pelo menos seis teodolitos do mesmo fabricante. Desses, somente dois restaram na coleção e, mesmo assim, o teodolito estudado (de número 1) apresentava partes que não eram originais e sim do teodolito de número 5 do mesmo grupo.

Também a partir das pesquisas históricas, constatou-se que a oficina do Observatório estava capacitada para consertos e manutenção de instrumentos científicos - e efetivamente os realizava -, mas, para esse fim, também eram utilizados os serviços de outras oficinas nacionais e no exterior.

A avaliação das peças do teodolito permitiu verificar que o nível fixo existente não era original, não pertencendo a esse tipo de instrumento fabricado por Brunner Frères. Por outro lado, pesquisas realizadas permitiram identificar um nível de cavalete existente na coleção do MAST como pertencente a esse teodolito e reintegrá-lo ao instrumento. Das peças ausentes (vidros, lente objetiva e lente ocular), somente os vidros despolidos puderam ser replicados.

A aplicação de verniz foi realizada de forma particular para cada peça, pois as exigências para uma melhor qualidade da camada de verniz estavam relacionadas ao formato da peça. A temperatura de secagem do verniz não se mostrou determinante na obtenção da coloração desejada. Por outro lado, o verniz produzido segundo receita proveniente do período histórico de fabricação do instrumento apresentou cor muito clara, necessitando de mistura com soluções concentradas de pigmentos (sangue de dragão e goma-guta) para atingir a cor desejada. Talvez o uso de componentes adquiridos no mercado nacional atual possa ter interferido na qualidade final do verniz produzido.

$\bigcirc$ processo de restauro realizado foi multidisciplinar, exigindo a interação entre várias áreas para que o melhor resultado fosse alcançado. Já o procedimento de intervenção propriamente dito foi completamente artesanal e exigiu o emprego de mão de obra especializada e treinada nas suas particularidades. $\bigcirc$ grau de dificuldade envolvido foi muito elevado e pode ser avaliado nas inúmeras tentativas realizadas com o intuito de dominar as técnicas envolvidas.

Finalmente, as inúmeras informações obtidas sobre o artefato e sua história, durante o processo de restauração, permitem considerar o momento da restauração como um fato singular na trajetória de qualquer instrumento. Pelas características das intervenções envolvidas, trata-se de uma fase onde o objeto pode ser reavaliado, tratado para que subsista por mais tempo, ou da qual pode 
sair alterado de forma irremediável, perdendo parcial ou integralmente o potencial documental que carrega.

\section{REFERÊNCIAS}

ARQUIVOS E SITE

Arquivo do Palácio do Itamarati

[OFÍCIO], 11 jan. 1909. Doc. 05 (numeração do Observatório Nacional) e 180 (numeração do Ministério das Relações Exteriores).

[OFÍCIO], 14 abr. 1887. Doc. 1249 (numeração do Ministério das Relações Exteriores).

Arquivo Nacional

OBSERVATÓRIO Astronômico. Microfilme. Rolo 002.0.83; Fundo: Série educação; Código do Fundo: 98; Notação: IE8 1 / IE8 2 / IE8 3; Seção de Guarda: Codes, 14 out. 1878; 6 fev. 1879.

Museu de Astronomia e Ciências Afins

Coordenação de Documentação em História da Ciência. Serviço de Arquivo de História da Ciência

CRULS, L. Comissão de Pernambuco (Olinda), Passagem de Vênus, Annales de l'Observatoire Imperial de Rio de Janeiro, Tomo III (1882a). Fundo: ON.

CRULS, L. Comissão Punta Arenas-Estreito Magalhães, Annales de l'Observatoire Imperial de Rio de Janeiro,Tomo III (1882b). Fundo: ON.

OFÍCIOS recebidos, comissão da Carta Geral do Império - 1875. Fundo: ON.

OFÍCIOS recebidos, 28 jun. 1879a. Fundo: ON. Doc. 1/1.

OFÍCIOS recebidos, 28 jun. 1879b. Fundo: ON. Documento sem numeração.

OFÍCIOS recebidos, 18 out. 1886. Fundo: ON. Doc. 9/1.

OFÍCIOS recebidos 1894, 20 fev. 1894. Fundo: ON Série 178. Documento sem numeração.

OFÍCIOS recebidos, 19 maio 1900. Fundo: ON. Doc. 3.

OFíCIOS recebidos 1901/1904, 20 mar. 1903. Fundo: ON. Documento sem numeração.

OFÍCIOS recebidos 1909, 2 jan. 1909. Fundo: ON. Doc. 322.

OFÍCIOS recebidos da Secretaria do Estado em 1912, 18 set. 1912. Fundo: ON. Doc. 3960.

OFÍCIOS recebidos 2. semestre 1912, 28 set. 1912. Fundo: ON. Doc. 27.

OFíCIOS remetidos 1900, 7 maio 1900. Fundo: ON. Doc. 47.

OFÍCIOS remetidos 2.Trimestre 1916, 11 jul. 1916. Fundo: ON. Doc. 432. 
OFÍCIOS remetidos 2.Trimestre 1923, 2 abr. 1923. Fundo: ON. Doc. 130.

REVISTA do Observatório Nacional, 1890.

Site da University of Chicago

Disponível em: <http://wwwcrl-jukebox.uchicago.edu/bsd/bsd/hartness/minopen.htm>

BRASIL. Relatório do Ministério dos Negócios do Império, maio 1883.

Relatório do Ministério das Relações Exteriores, 1900.

Relatório anual de atividades da Secretaria de Estado dos Negocios da Agricultura, Commercio e Obras, 1876-1.

Relatório anual de atividades da Secretaria de Estado dos Negocios da Agricultura, Commercio e Obras, 1876-2.

\section{LIVROS E PERIÓDICOS}

ALBERTI, Samuel J. J. M. Objects and the museum. Isis, Chicago, v. 96, p. 559-571, 2005.

BARRIO, Néstor. O exame da fluorescência da pintura. In: MENDES, Marylka; BAPTISTA, Antonio Carlos N. Restauração: ciência e arte. Rio de Janeiro: Editora UFRJ; Iphan, 1996. p. 285-322.

BENNETT, Jim A. The divided circle: a history of instruments for Astronomy, Navigation and Surveying. Oxford: Phaidon, 2000.

Museums and the History of Science. Isis, Chicago, v. 96, p. 602-608, 2005.

BIRAUD, Guy. La restauration et la conservation des appareils scientifiques de collection: appareils de physique, radios e phonographes. Paris: Biraud; Societé Historique de Radio, 1987.

BRENNI, Paolo. Cleaning and relacquering of brass scientific instruments. Bulletin of Scientific Instrument Society, London, n. 10, p. 2-3, 1986.

$19^{\text {th }}$ Century French Scientific Instrument Makers:The Brunners and Paul Gautier. Bulletin of Scientific Instrument Society, London, n. 49, p. 38, 1996.

Better than new? Scientific instrument restoration in Italy. In: ISTITUTO E MUSEO DI STORIA DELLA SCIENZA (Org.). The restoration of scientific instruments: proceedings of the workshop held in Florence, December 14-15, 1998. Florence: Le Lettere, 1999. p. 89-97.

Instruments in South America: the Collection of the Museu de Astronomia e Ciências Afins of Rio de Janeiro. Bulletin of the Scientifique Instrument Society, London, n. 65, p. 25-28, 2000.

CÂMARA, Roberta N. da. A patrimonialização de material genético brasileiro: o estudo de caso da coleção de fungos filamentosos do Instituto Oswaldo Cruz. 2008. Dissertação (Mestrado em Museologia e Patrimônio) - Programa de Pós-Graduação em Museologia e Patrimônio, Universidade Federal do Estado do Rio de Janeiro; Museu de Astronomia e Ciências Afins, Rio de Janeiro, 2008. Disponível em: <http://www.unirio.br/cch/ppg-pmus/>.

CLENDINNING, James. Principles and use of surveying instruments. 2. ed. London: Blackie, 1966. 
COOPER, Michael. From graduations on metal to binary biphase modulation, or from land and hydrographic surveying to geomatics. Bulletin of the Scientific Instrument Society, London, n.72, p. 2-10, 2002.

FURTADO, Janaina L. Objetos, coleções e biografia: a história do laboratório de química do Imperial Observatório do Rio de Janeiro. In: GRANATO, Marcus; RANGEL, Marcio F. Cultura Material e Patrimônio de CET. Rio de Janeiro: MAST, 2009. p. 154-174.

GONÇALVES, José Reginaldo S. Autenticidade, memória e ideologia nacionais: o problema dos patrimônios culturais. In: FRY, Peter; ESTERCI, Neide; GOLDENBERG, Miriam (Org.). Fazendo antropologia no Brasil, 1. Rio de Janeiro: DP\&A; Capes, 2001, p. 15-33.

GRANATO, Marcus. A restauração de instrumentos científicos bistóricos. 2003. Tese (Doutorado em Engenharia Metalúrgica e de Materiais) - Coordenação dos Programas de Pós Graduação em Engenharia, Universidade Federal do Rio de Janeiro, 2003.

; BRITO, Jusselma D. de; SUZUKI, Cristiane. Restauração do pavilhão, cúpula metálica e luneta equatorial de $32 \mathrm{~cm}$ - conjunto arquitetônico do Museu de Astronomia e Ciências Afins (MAST). Anais do Museu Paulista, São Paulo, v. 13, n.1, p. 273-311, 2005.

; SANTOS, Leandro R. dos; MIRANDA, Luis Roberto M. de. Estudo sobre a conservação de instrumentos científicos históricos no Museu de Astronomia e Ciências Afins (MAST). Cadernos do Ceom (Unoesc), Maringá, v. 21, p. 243-274, 2006.

; TULLY, Françoise Le Guet. Les principes de la restauration d'instruments scientifiques: le cas du cercle méridien Gautier de l'observatoire de Rio de Janeiro. In Situ: le patrimoine scientifique, Paris, v. 10, p. 1-34, mai 2009.

GUILHOBEL, José Cândido, Capitão-Tenente. Tratado de Geodesia. Rio de Janeiro:Typographia à vapor, 1879.

KEENE, Suzanne. Instruments of History: appearance and evidence. In: ISTITUTO E MUSEO DI STORIA DELLA SCIENZA (Org.). The restoration of scientific instruments: proceedings of the workshop held in Florence, December 14-15, 1998. Florence: Le Lettere, 1999. p. 57-68.

KING, Henry C. The bistory of the telescope. New York: Dover, 1979.

MINIATI, Mara; BRENNI, Paolo. Restauro di strumenti storico-scientifici e filosofie di intervento. In: BITELLI, Luisa Masetti (Org.). Restauro di strumenti $i$ materialli: scienza, musica, etnografia. Firenze: Nardini, 1993. p. 51-57.

MOHEN, Jean-Pierre. Les sciences du patrimoine: identifier, conserver, restaurer. Paris: Odile Jacob, 1999. p. 181-232.

MOURÃO, Ronaldo R. de F. Dicionário enciclopédico de astronomia e astronáutica. Rio de Janeiro: Nova Fronteira, 1995.

MORIZE, Henrique Ch. Posição geográfica de Queluz e Ouro Preto. Revista do Observatório Nacional, Rio de Janeiro, 1906.

OLIVEIRA, Maria Alice C. de. A trajetória da formação da Coleção de Objetos de CET do Observatório do Valongo. 2011. Dissertação (Mestrado em Museologia e Patrimônio) - Programa de Pós-Graduação em Museologia e Patrimônio, Universidade Federal do Estado do Rio de Janeiro; Museu de Astronomia e Ciências Afins, Rio de Janeiro, 2011. 
PEARSALL, Ronald. Collecting and restoring scientific instruments. Newton Abbot: David \& Charles, 1974.

TULLY, Françoise Le Guet; FRANÇOISE, Joël; MOUREY,William. L'Observatoire de Nice Côte d'Azur, site de Nice. Projets e réalizations. In: MOUREY,William; ROBBIOLA, Luc (Org.). Metal'98: Proceedings of the international conference on metals conservation, Draguignan, Figanières, France, 27-29 May 1998. London: James \& James, 1998. p. 22-25.

VIEIRA, Felipe Koeller R. Patrimônio aeronáutico: presenças e ausências no Museu Aeroespacial brasileiro. 2009. Dissertação (Mestrado em Museologia e Patrimônio) - Programa de Pós-Graduação em Museologia e Patrimônio, Universidade Federal do Estado do Rio de Janeiro; Museu de Astronomia e Ciências Afins, Rio de Janeiro, 2009. Disponível em: <http://www.unirio.br/cch/ ppg-pmus/>.

VIÑAS, Salvador Muñoz. Contemporary Theory of Conservation. Oxford: Elsevier, 2005.

Artigo apresentado em 3/2011. Aprovado em 5/2011. 